\title{
Associations between Second-Hand Tobacco Smoke Exposure and Cardiorespiratory Fitness, Physical Activity, and Respiratory Health in Children
}

\author{
Melissa Parnell ${ }^{1}$, Lawrence Foweather ${ }^{2, *(\mathbb{D})}$, Greg Whyte ${ }^{2}$, John Dickinson ${ }^{3}\left(\mathbb{D}\right.$ and Ivan Gee ${ }^{1(D)}$ \\ 1 Public Health Institute, Liverpool John Moores University, Liverpool L2 2QP, UK; \\ melissajparnell@hotmail.com (M.P.); I.L.Gee@ljmu.ac.uk (I.G.) \\ 2 Research Institute for Sport and Exercise Sciences, Liverpool John Moores University, Liverpool L3 3AF, UK; \\ G.Whyte@ljmu.ac.uk \\ 3 School of Sport and Exercise Sciences, University of Kent, Medway ME4 4AG, UK; j.w.dickinson@kent.ac.uk \\ * Correspondence: L.Foweather@ljmu.ac.uk; Tel.: +44-(0)151-231-4152
}

Citation: Parnell, M.; Foweather, L.; Whyte, G.; Dickinson, J.; Gee, I. Associations between Second-Hand Tobacco Smoke Exposure and Cardiorespiratory Fitness, Physical Activity, and Respiratory Health in Children. Int. J. Environ. Res. Public Health 2021, 18, 11445. https:// doi.org/10.3390/ijerph182111445

Academic Editors: Michael J. Duncan, Cain Clark, Clarice Maria De Lucena Martins and Jorge Mota

Received: 18 September 2021

Accepted: 25 October 2021

Published: 30 October 202

Publisher's Note: MDPI stays neutral with regard to jurisdictional claims in published maps and institutional affiliations.

Copyright: (c) 2021 by the authors. Licensee MDPI, Basel, Switzerland. This article is an open access article distributed under the terms and conditions of the Creative Commons Attribution (CC BY) license (https:// creativecommons.org/licenses/by/ $4.0 /)$.

\begin{abstract}
Background: Cardiorespiratory fitness (CRF) and physical activity (PA) are associated with a plethora of positive health effects. Many UK children fail to meet the recommended level of PA, with an observed decline in CRF levels over recent decades. Second-hand tobacco smoke (SHS) is responsible for a significant proportion of the worldwide burden of disease, but little is understood regarding the impact of SHS exposure on CRF and PA in children. The aim of this study was to test the associations between SHS exposure and CRF, PA, and respiratory health in children. Method: Children (9-11 years) from UK primary schools in deprived areas participated ( $\mathrm{n}=104,38$ smoking households). Surveys determined household smoking, and exhaled carbon monoxide was used to indicate children's recent SHS exposure. CRF $\left(\mathrm{VO}_{2 \text { peak }}\right)$ was assessed via maximal treadmill protocol using breath-by-breath analysis. Fractional exhaled nitric oxide and spirometry were utilised as indicators of respiratory health. Results: Linear regression models demonstrated that SHS exposure was negatively associated with allometrically scaled $\mathrm{VO}_{2 \text { peak }}(B=-3.8, p=0.030)$ but not PA or respiratory health. Conclusion: The results indicate that SHS is detrimental to children's CRF; given that approximately one-third of children are regularly exposed to SHS, this important finding has implications for both public health and the sport and exercise sciences.
\end{abstract}

Keywords: cardiorespiratory fitness; physical activity; second-hand smoke; children; $\mathrm{VO}_{2 \text { peak }}$; respiratory health; low socioeconomic status

\section{Introduction}

\subsection{Cardiorespiratory Fitness and Physical Activity}

Cardiorespiratory fitness (CRF) is a health-related component of physical fitness and defined as the ability of the circulatory, respiratory, and muscular systems to supply oxygen during sustained physical activity [1]. Accordingly, CRF is commonly employed as a global measure of health [1,2]. CRF is an important marker of physical and mental health, as well as academic achievement in youth [3,4], which reinforces the importance of early intervention efforts to promote CRF. In high and upper-middle income countries, there was a substantial decline in CRF for children and adolescents between the 1980s and 2000 [5]. In the North West of England, CRF in children has been decreasing since the 1990s [6,7]. Low levels of CRF and a temporal reduction in CRF are therefore suggestive of a decline in population health [5]. Physical activity (PA), in particular moderate-to-vigorous-intensity PA (MVPA), is positively associated with CRF [8,9], and low PA in childhood is predictive of low PA in adulthood [10,11]. The United Kingdom (UK) Chief Medical Officers' guidelines state that children and youth aged 5-18 years should achieve at least an average of $60 \mathrm{~min}$ of MVPA daily [12], yet less than half of all children and young people met these guidelines 
in England in 2019 [13]. Lower socioeconomic status (SES) has been shown to be associated with lower levels of PA $[14,15]$ and CRF $[16,17]$ in youth. It is therefore important to understand factors that influence CRF and PA in youth from areas of high deprivation to design effective interventions.

\subsection{Second-Hand Tobacco Smoke}

Tobacco smoke is a toxic and carcinogenic mixture of over 5000 different chemicals [18]. Second-hand smoke (SHS), often referred to as environmental tobacco smoke, is composed primarily of smoke that emanates from the end of the burning cigarette (sidestream smoke), smoke that the smoker inhales and exhales (mainstream smoke), and contaminants that diffuse through the cigarette paper $[19,20]$. SHS is responsible for a substantial proportion of global mortality and morbidity for both adults and children [21,22], with 1.2 million deaths attributable to SHS exposure in 2017, of which 5\% occurred in children under 10 years [23]. Children are particularly susceptible to the effects of SHS due to their high respiratory rates and immature organs [24]. Exposed children are at increased risk of chronic airway inflammation, lung function defects [25], severe asthma attacks, respiratory infections, ear infections, sudden infant death syndrome [26], and increased risk of hospitalisation in asthmatics [27].

The Smoke-free Legislation, which came into effect in England in July 2007 as a result of the Health Act 2006 [28], made it illegal to smoke tobacco in enclosed places, though smoking is still permitted in private residences and open public places. Indeed, two main determinants of children's SHS exposure are smoking by parents or caregivers and whether smoking occurs in the home [29]. In 2019, 15.9\% of UK men (3.8 million) and $12.5 \%$ of women (3.1 million) reported being current smokers [30]. While children's exposure to SHS has declined in England by 79\% since 1998 due to the emerging social norm of smokefree homes [31], UK-based studies have shown approximately $31.5 \%$ of children to have detectable levels of salivary cotinine, an indication of recent tobacco smoke exposure [31], with $96.9 \%$ of children from the poorest families demonstrating detectable levels of salivary cotinine [32]. Children from low socioeconomic status (SES) are therefore more likely to be exposed to SHS [32,33], and consequently more likely to suffer the detrimental impacts of SHS exposure.

\subsection{Second-Hand Tobacco Smoke, Cardiorespiratory Fitness, and Physical Activity}

The impact of SHS exposure on cardiorespiratory fitness has been studied in adults, with SHS exposure associated with reduced exercise performance [34,35] and reduced $\mathrm{VO}_{2 \max }$ [36]. Two main constituents of cigarette smoke, nicotine and carbon monoxide (amongst others), exhibit toxic effects on cardiovascular function both at rest and during exercise in adults [37]. For children and young people, research is limited. Of the research that exists, studies have found children's CRF (measured by maximal cycle ergometer test) to be significantly reduced for those with smoking parents [38], adolescents exposed to SHS to have increased systolic blood pressure whilst exercising [39], and obese children exposed to SHS were found to have reduced performance on a six-minute walk test [40]. PA has been shown to reduce adolescent smoking uptake [41] and aid cessation [42], but there is limited research exploring the association between SHS exposure, or having a smoking family member, on children's engagement in PA. Further research is therefore required to examine the association between SHS exposure, cardiorespiratory fitness, and PA in children. Given that the respiratory system is important for CRF and PA, and that SHS exposure has been found to be associated with increased risk of respiratory disease [25-27], examining the association between smoking exposure and markers of respiratory health is also important. Understanding whether household SHS exposure is detrimental to children's CRF, PA, and respiratory health will be of value in the domain of public health and could provide novel pathways for health promotion interventions. 


\subsection{Aim}

The aim of this study was to examine whether SHS exposure in the home is associated with children's (i) cardiorespiratory fitness, (ii) participation in physical activity, and (iii) markers of respiratory health.

\section{Materials and Methods}

\subsection{Study Design}

This cross-sectional study was granted ethical approval by the University Research Ethics Committee (Ref: 16/PBH/001) and comprises the quantitative aspect of a larger mixed-methods research project [43]. Data collection began in September 2017 and ended in February 2019, with schools participating at different timepoints throughout the year and determined according to convenience relative to the schools. The wider project recruitment and data collection process is demonstrated in the Supplementary Materials S1.

\subsection{Participants and Setting}

Participants were targeted as being aged 9-11 years old and in year 5 or 6 at a statefunded primary school within two metropolitan boroughs in Northwest England. This age group was targeted since evidence from Northwest England has reported low fitness among primary school children [6], and therefore this study sought to examine whether smoking exposure was a factor. One-hundred-and-forty-seven primary schools were contacted across the region via an email containing study information, followed by a phone call. Gatekeepers (headteachers) were provided with information sheets and face-to-face meetings were organised with representatives from primary schools. Participating schools received informational presentations, during which children were free to ask questions about the study. Information packs containing participant information sheets for children and parents, child medical questionnaires, parental surveys, and parental consent and child assent forms were then distributed to all parents and guardians. Parental consent, child assent, and completed medical questionnaires were required to participate in the study. Exclusion criteria were any medical conditions that limit a child's ability run on a treadmill.

\subsection{Data Collection Procedures}

Following parental consent, child assent, and completed parental surveys, exhaled carbon monoxide measurements were taken at the primary school, on the morning of the visit to the University laboratories. Participants were then transported to the laboratories in small groups of 3-4 children during school time (09:00-15:00). Once at the University, participants' anthropometrics were measured. Respiratory health markers including fractional exhaled nitric oxide measurements and spirometry were subsequently taken. Finally, children participated in cardiorespiratory fitness testing once all respiratory measures had been completed. In between laboratory measures, children completed a self-report physical activity survey.

\subsection{Measures}

\subsubsection{Demographic Information}

Participant (adult and child) demographic information, including parental education, child age and ethnicity, and home postcode, was obtained via the parental survey. Household deprivation was assessed via the English Indices of Multiple Deprivation (EIMD) [44] using the participant's home postcode and the Ministry of Housing, Communities, and Local Government postcode look-up tool [44].

\subsubsection{Second-Hand Smoke Exposure}

Parents or guardians self-reported household smoking status in the parental survey. Items were adapted from the well Global Adult Tobacco Survey (GATS) by the Global Adult Tobacco Survey Collaborative Group [45] and determined the number of tobacco 
smokers living in the home, as well as the rooms in which smoking occurred and/or was permitted, and how many cigarettes were smoked each day per person. The GATS is a well validated and reliable, globally standardised survey used to collect tobacco-related information [45]. Space was provided for participants to include information regarding smoking habits for up to four members of the household, with more space available upon request. Similar information was collected for e-cigarette use. Participants were classified into 'non-smoking household' or 'smoking household' according to whether a household member smoked cigarettes or not, regardless of where smoking was permitted. Households with an adult that used e-cigarettes were classified as non-smoking, as no significant differences in fitness and health outcomes were observed between children from non-smoking and e-cigarette-using households. Households were then further classified as permitting smoking 'indoors' or 'outdoors only'.

Exhaled carbon monoxide (eCO) was measured in ppm using a breath Smokerlyzer PiCO device (Bedfont, UK) to determine children's recent tobacco smoke exposure. Previous studies have shown eCO to be a useful indicator for recent tobacco smoke exposure in adults [46-48] and youth [49]. A threshold of 3-4 ppm is suggested to distinguish smokers from non-smokers [46], but there is currently little research regarding thresholds for children who are exposed to SHS. Pilot work indicated that eCO declined within several hours post-tobacco smoke exposure. Therefore, carbon monoxide (CO) measurements were taken on the morning (08:30) of laboratory visits, at school prior to departure, to better reflect second-hand smoke exposure from the home (mean value of two attempts). Participants were asked to hold their breath for $15 \mathrm{~s}$ before exhaling continuously with a constant force into the Smokerlyzer mouthpiece.

\subsubsection{Anthropometry}

All anthropometric assessments were conducted on arrival to the University laboratories in accordance with the standards of the International Society for the Advancement of Kinathropometry [50]. Children were assessed whilst wearing light clothing and shoes removed. Body mass to the nearest $0.1 \mathrm{~kg}$ (Seca, Birmingham, UK), stature, and sitting stature to the nearest $0.1 \mathrm{~cm}$ (Seca, Birmingham, UK) were assessed using standard techniques [51]. Body mass index (BMI) was calculated from stature and mass $\left(\mathrm{kg} \cdot \mathrm{m}^{2}\right)$ with age- and sex-specific International Obesity Task Force BMI cut-offs used to classify child BMI and weight status for descriptive purposes [52]. Years to peak height velocity, a somatic indicator of physical maturity, was estimated using stature, sitting height, and body mass [53].

\subsubsection{Physical Activity}

Children completed the Physical Activity Questionnaire for Children (PAQ-C) [54]. The PAQ-C requests responses for the last 7 days by asking participants to check a list of activities for frequency of participation, including PA during school time and out of school [55]. Each question is scored from 1 to 5, for example, Question 10: On the last weekend, how many times did you participate in sports, dance, or play games in which you were very active? (Tick one). 'None' would equal a score of 1 , and '6 or 7 times last week' would give a score of 5 . A mean is calculated for all questions to give an overall PAQ-C score. The PAQ-C is a validated and reliable measure of PA levels in children regularly used in PA surveillance [54-56].

\subsubsection{Respiratory Health}

Fractional exhaled nitric oxide (FeNO), an indication of airway inflammation, was measured (mean value of two attempts) at rest using a NIOX ${ }^{\circledR}$ VERO device (Circassia, UK). This measured FeNO in the exhaled breath, at rest, at a constant flow rate of $50 \mathrm{~mL} / \mathrm{min}$. FeNO was performed prior to spirometry measures to avoid potential carryover effects [57] and taken as the mean of duplicate measures [58]. FeNO offers additional benefits to spirometry by detecting eosinophilic airway inflammation [58], an indication of asthma [59]. 
The non-invasiveness and instantaneous result make FeNO a suitable method for assessing lung health in children [60]. For children, the following FeNO thresholds were used: $<20$ ppb (low), 20-35 ppb (intermediate), and $>35$ ppb (high) [58].

Spirometry measures including forced vital capacity (FVC), forced expiratory volume (FEV1), peak expiratory flow (PEF), and forced expiratory ratio (FER) were taken at rest using a digital micro-spirometer (Micro-plus spirometer, CareFusion, UK). Measurements were made in triplicate and the best value compared against predicted values for sex, height, and age [61]. Spirometry values were normalised by a factor of 0.9 for black children and 0.95 for children of other ethnicities [62]. Spirometry values were then expressed as percentages of predicted for sex, age, height, and ethnicity. An FEV1 < 80\% and FER < 70\% predicted was considered obstructive, and FEV1 < 60\% and FVC $<60 \%$ was considered restrictive [63]. Information regarding respiratory disease including asthma (and general medical background) was collected via medical questionnaire.

\subsubsection{Cardiorespiratory Fitness}

Cardiorespiratory fitness (CRF), using peak oxygen uptake $\left(\mathrm{VO}_{2 \text { peak }}\right)$ as a marker, was assessed using an individually calibrated, discontinuous incremental treadmill test to volitional exhaustion using breath-by-breath analysis (Jaeger Oxycon Pro, Viasys Health Care, UK). Peak oxygen uptake $\left(\mathrm{VO}_{2 \text { peak }}\right)$, as opposed to $\mathrm{VO}_{2 \max }$ (maximal oxygen uptake), was used as children often fail to reach a plateau [64]. Previous studies have demonstrated that 'true' $\mathrm{VO}_{2 \max }$ values can be achieved in children without the need for plateau as long as test endpoints are met [65]. The following method is based on an established protocol and is supported by previous work [66].

A paediatric facemask (Hans Rudolph, Kansas City) covering the nose and mouth was secured via an adjustable nylon harness prior to the test beginning. Before using the treadmill, participants wore a specialised harness that would cause the treadmill to stop in case of any trips or falls. Children underwent a familiarisation period of walking and running on the treadmill prior to the test. To account for differences in age and limb length, $\mathrm{VO}_{2 \text { peak }}$ test speeds were individually calibrated by anchoring treadmill speeds to set Froude (Fr) numbers [67]. Participants completed 2-min stages, stage one speed at Fr 0.25, stage two speed at Fr 0.5, with each additional stage determined by the difference in speed for stages one and two $(\sim 2 \mathrm{~km} / \mathrm{h})$. The treadmill remained at $1 \%$ gradient throughout. The test was terminated at the point of volitional exhaustion when the participant was unable to continue despite strong verbal encouragement.

Oxygen uptake $\left(\mathrm{VO}_{2}\right)$ and carbon dioxide production $\left(\mathrm{VCO}_{2}\right)$ were measured breathby-breath with an online system (Jaeger Oxycon Pro, Viasys Health Care, Warwick, UK). Prior to each testing session, the Oxycon Pro system was calibrated using known volumes of gases $\left(0.5 \% \mathrm{CO}_{2}\right.$ and $\left.20.5 \% \mathrm{O}_{2}\right)$ and known volumes $(3.0 \mathrm{~L} / \mathrm{s})$. Heart rate was monitored continuously (Polar, Kempele, Finland).

$\mathrm{VO}_{2 \text { peak }}$ was defined as the highest $15 \mathrm{~s}$ averaged oxygen uptake achieved during the test when participants reach volitional exhaustion, and the below endpoints met. $\mathrm{VO}_{2 \text { peak }}$ was accepted as the maximal index when participants exhibited any of the following subjective indicators of maximal effort; unsteady gait, hyperpnea, facial flushing, sweating, in addition to objective indicators: respiratory exchange ratio (RER) $>1.05$ and heart rate $>199$ beats / $\mathrm{min}[66]$.

The Pictorial Children's Effort Rating Table (PCERT) [68] was used to establish participants' perceived exertion. The PCERT uses pictures as well as numbers and descriptive language, reflecting the changing physiological demands of the exercise task in a childfriendly format [69]. Participants were asked to state or point to the point on the scale that best described their effort rating at the end of each two-minute stage.

Most research to date has expressed CRF as $\mathrm{VO}_{2 \text { peak }}$ ratio scaled for mass $\left(\mathrm{mL} \cdot \mathrm{kg}^{-1} \cdot \mathrm{min}^{-1}\right)$, but expressing CRF in this way over-scales for mass and leads to spurious correlations with other health-related outcomes [70]. CRF was presented as allometrically scaled $\mathrm{VO}_{2 \text { peak }}$ using a sample-specific calculated mass exponent $\left(\mathrm{mL} \cdot \mathrm{kg}^{-0.53} \cdot \mathrm{min}^{-1}\right)$. Data for 
absolute $\mathrm{VO}_{2 \text { peak }}\left(\mathrm{mL} \cdot \mathrm{min}^{-1}\right)$ and $\mathrm{VO}_{2 \text { peak }}$ ratio scaled by body mass $\left(\mathrm{mL} \cdot \mathrm{kg}^{-1} \cdot \mathrm{min}^{-1}\right)$ are provided within the Supplementary Materials. Mass exponents were calculated using log-linear regression models of mass and absolute $\mathrm{VO}_{2 \text { peak }}$, as described by Welsman and Armstrong [70], where the generated ' $b$ ' is the mass exponent. Sex- and age-group-specific exponents were not calculated due to the small sample size. The generated mass exponent $(0.53)$ was 'tested' by correlational analysis between allometrically scaled absolute $\mathrm{VO}_{2 \text { peak }}$ and mass, which was found to be close to zero $(r=-0.046, p=0.663)$, indicating the influence of mass was successfully removed.

For descriptive purposes, participants were classified as fit or unfit according to published thresholds for identifying aerobic fitness and associated cardio-metabolic disease. Thresholds used were taken from the review by Lang et al. [71], which incorporates data from 1,142,026 youth from 50 countries. $\mathrm{VO}_{2 \text { peak }}$ scores below $42 \mathrm{~mL} \cdot \mathrm{kg}^{-1} \cdot \mathrm{min}^{-1}$ for boys and $35 \mathrm{~mL} \cdot \mathrm{kg}^{-1} \cdot \mathrm{min}^{-1}$ for girls indicate higher risk of cardiovascular disease and were classified as unfit.

\subsection{Statistical Methods}

Statistical analyses were performed using SPSS for Windows (version 26; SPSS, Chicago, IL, USA). Data are expressed as mean \pm standard deviation unless otherwise stated. Data that were not normally distributed were base-10 logarithm transformed (EIMD), natural log transformed (FeNO), or square root transformed (total number of cigarettes smoked per day) prior to analysis, although are presented pre-transformation, with geometric mean and geometric standard deviation, in descriptive tables for ease of interpretation. Differences by sex and household smoking status were assessed using independent sample Student's $t$-tests and are provided within the Supplementary Materials S2 and S3.

Unadjusted and adjusted multiple linear regression models were performed for allometrically scaled $\mathrm{VO}_{2 \text { peak }}, \mathrm{PA}$, and each of the markers of respiratory health (FEV1\%, $\mathrm{FVC} \%, \mathrm{PEF} \%$, FER, and FeNO), to assess if these outcome variables were predicted by household smoking. The forced entry (enter) method was selected over the stepwise method in order to include known correlates based on theoretical knowledge and past research, and to ensure the researcher had control over what variables were entered into the models [72].

While several indicators of household smoking status and level of smoking were available, the number of cigarettes smoked per day per household was selected as a more precise measure of household exposure than the binary measure of household smoking status (smoking or non-smoking). Household smoking status was not entered into the regression models, in addition to the number of cigarettes smoked, due to the high correlation $(r>0.9)$ between these two variables. Exhaled CO was not significantly different for children from smoking and non-smoking homes $(p=0.215)$, and was not correlated with the number of cigarettes smoked per day $(r=0.157, p=0.119)$; similar findings have been observed in children in previous studies [73]. Exhaled $\mathrm{CO}$ was therefore deemed inappropriate as a measure of second-hand smoke exposure in children for the present study and was not used in the predictive models. ANOVA and Tukey post hoc analysis determined that CRF, PA, and respiratory variables for children from non-smoking and e-cigarette-using families were not statistically different and therefore e-cigarette use was further classified as non-smoking.

All unadjusted models included the sole predictor of the square root transformed number of cigarettes smoked per day. Other variables were selected based on known determinants from previous research. For allometrically scaled $\mathrm{VO}_{2 \text { peak, }}$ sex, age, stature, maturation, PA, and deprivation (logEIMD) [74] were included in the adjusted model. Mass was not included in the models as mass is already accounted for within the calculation for allometric scaling. PA models contained known determinants of PA including sex, age, $\mathrm{BMI}$, maturation, and deprivation (logEIMD) [75-77]. As spirometry measures, $\mathrm{FEV}_{1} \%$, $\mathrm{FVC} \%$, and $\mathrm{PEF} \%$ values were already adjusted for known determinants of lung function prior to modelling (i.e., sex, age, height, and ethnicity), adjusted linear regressions for 
these measures included mass, diagnosed asthma, and deprivation (logEIMD) [58,61,78]. Linear regressions for FER additionally included age, sex, and stature as FER values are not presented as percentages of predicted. Linear regressions for FeNO included sex, age, mass, stature, asthma diagnoses, and deprivation (logEIMD) [58,78].

For all models, there was linearity, as assessed by partial regression plots and a plot of studentized residuals against the predicted values. There was homoscedasticity, as assessed by visual inspection of a plot of studentized residuals versus unstandardized predicted values. There was no evidence of multicollinearity as assessed by tolerance values greater than 0.1 . Studentized deleted residuals greater than \pm 3 standard deviations were excluded from absolute $\mathrm{VO}_{2 \text { peak }}(\mathrm{n}=4), \operatorname{PEF} \%(\mathrm{n}=1)$, and FER $(\mathrm{n}=2)$. There were no leverage values greater than 0.2 and no values for Cook's distance above 1 . The assumption of normality was met, as assessed by a histogram and P-P Plot.

\section{Results}

\subsection{Participant Descriptives}

\subsubsection{Sampling}

Of the 147 schools contacted across the Merseyside region, four schools (two each from both Liverpool and Wirral areas) participated in the study ( $3 \%$ response rate). Schools that declined to participate provided a variety of reasons such as 'too busy', 'no staff available to coordinate the project', and 'the project is too contentious due to the smoking focus'. Total participation (consent rate) was $26.7 \%$ with 104 children taking part (46 boys, 58 girls) out of a possible 390 invited from the participating schools.

Out of the 104 participants with written parental consent and participant assent, ten children were excluded from the $\mathrm{VO}_{2 \text { peak }}$ analysis for failing to reach 'peak' threshold criteria $(n=7)$, being unable to run on the day $(n=2)$, and one participant requested not to undertake the fitness assessment. In total, 94 children ( 43 boys, 51 girls) were included in the $\mathrm{VO}_{2 \text { peak }}$ analysis. One participant requested not to be weighed or have their height measured. Four participants had no corresponding exhaled carbon monoxide data due to unavailability at the time of testing. Eleven participants failed to provide a home postcode, or the provided postcode did not generate an EIMD score, and therefore school postcode was used as a substitute. Two children failed to perform a successful FeNO test. In total, complete data were available for 92 participants. Participant characteristics are presented in Table 1. Descriptive data by gender and household smoking status are provided in the Supplementary Materials S2 and S3.

\subsubsection{Participant Demographics and Weight Classification}

The geometric mean English Indices for Multiple Deprivation (EIMD) rank was 1427 (geometric SD 5652) and most participants' postcodes were within the first (69.2\%) and second $(16.3 \%)$ most deprived deciles. All four primary postcodes were within areas of very high deprivation (1st decile). The percentage of parents or guardians with no formal education was 3.3\%, 33.7\% were educated to high school level, $41.3 \%$ had completed college or sixth form, $13.0 \%$ had a Bachelor's degree, and $8.7 \%$ had a Master's degree or above. White British children made up $76.9 \%$ of the sample population, with 6.7\% Black British, 2.9\% White Polish, 1.9\% White Portuguese, 1.9\% Black African, 1\% Black other, $1 \%$ Chinese British, and $7.7 \%$ other. Overall, out of 103 children $(\mathrm{n}=58$ girls and 45 boys), $35.0 \%$ were overweight or obese, including $28.9 \%$ of boys and $39.7 \%$ of girls. Further descriptive data regarding socioeconomic and weight status are provided in the Supplementary Materials S5, S6, respectively. 
Table 1. Descriptive statistics for the sample.

\begin{tabular}{|c|c|c|c|c|c|}
\hline & $\mathbf{N}$ & Minimum & Maximum & Mean & SD \\
\hline \multicolumn{6}{|l|}{ Anthropometry } \\
\hline Decimal age (years) & 104 & 8.5 & 11.5 & 10.1 & 0.6 \\
\hline Maturation (years to PHV) & 103 & -4.1 & 0.1 & -2.2 & 1.0 \\
\hline Stature $(\mathrm{cm})$ & 103 & 122.0 & 158.0 & 141.7 & 6.6 \\
\hline Mass (kg) & 103 & 22.8 & 66.0 & 38.2 & 9.2 \\
\hline BMI $\left(\mathrm{kg} \cdot \mathrm{m}^{-2}\right)$ & 103 & 13.2 & 30.5 & 19.0 & 3.9 \\
\hline \multicolumn{6}{|l|}{ Cardiorespiratory fitness } \\
\hline $\mathrm{VO}_{2 \text { peak }}\left(\mathrm{mL} \cdot \mathrm{min}^{-1}\right)$ & 94 & 843.0 & 2399.0 & 1659.5 & 307.9 \\
\hline $\mathrm{VO}_{2 \text { peak }}\left(\mathrm{mL} \cdot \mathrm{kg}^{-1} \cdot \mathrm{min}^{-1}\right)$ & 94 & 24.8 & 59.5 & 45.0 & 7.7 \\
\hline $\mathrm{VO}_{2 \text { peak }}\left(\mathrm{mL} \cdot \mathrm{kg}^{-0.53} \cdot \mathrm{min}^{-1}\right)$ & 94 & 157.5 & 322.6 & 247.2 & 36.3 \\
\hline \multicolumn{6}{|l|}{ Respiratory health } \\
\hline $\mathrm{FEV}_{1}(\%)$ & 103 & 43.9 & 131.7 & 83.0 & 17.2 \\
\hline FVC $(\%)$ & 103 & 44.3 & 136.0 & 89.0 & 19.7 \\
\hline PEF (\%) & 103 & 33.6 & 155.7 & 75.3 & 21.0 \\
\hline $\mathrm{FEV}_{1} / \mathrm{FVC}$ & 103 & 52.7 & 100.0 & 89.6 & 11.0 \\
\hline $\mathrm{FeNO} *(\mathrm{ppb})$ & 102 & $<5$ & 147 & 15.9 & 33.4 \\
\hline \multicolumn{6}{|l|}{ Physical activity } \\
\hline PAQ-C & 103 & 2.1 & 5.0 & 3.6 & 0.7 \\
\hline \multicolumn{6}{|l|}{ SHS exposure } \\
\hline $\mathrm{eCO}(\mathrm{ppm})$ & 100 & 0 & 7 & 1.8 & 1.2 \\
\hline Cigarettes per day & 104 & 0 & 65 & 5.5 & 10.8 \\
\hline \multicolumn{6}{|l|}{ Deprivation } \\
\hline EIMD rank * & 104 & 69 & 25,530 & 1427 & 5652 \\
\hline
\end{tabular}

PHV = peak height velocity, BMI = body mass index; Spirometry values expressed as percentage of predicted values for sex, age, ethnicity, and height. $\mathrm{FEV}_{1}=$ forced expiratory volume in $1 \mathrm{~s}, \mathrm{FVC}=$ forced vital capacity, $\mathrm{PEF}=$ peak expiratory flow, $\mathrm{FeNO}=$ fractional exhaled nitric oxide, $\mathrm{eCO}=$ exhaled carbon monoxide, EIMD = English Indices of Multiple Deprivation, maturation = years from peak height velocity. Physical activity (PAQ-C) is scored between 1 and 5 , with 5 being the most active, SHS = Second-hand smoke exposure, EIMD = English Indices of Multiple Deprivation. ${ }^{*}$ Indicates geometric mean and geometric standard deviation.

\subsubsection{Cardiorespiratory Fitness}

Participants could be classified as fit or unfit according to established thresholds [71] based on ratio scaled $\mathrm{VO}_{2 \text { peak }}\left(\mathrm{mL} \cdot \mathrm{kg}^{-1} \cdot \mathrm{min}^{-1}\right)$. Using the CRF thresholds of $42 \mathrm{~mL} \cdot \mathrm{kg}^{-1} \cdot \mathrm{min}^{-1}$ for boys and $35 \mathrm{~mL} \cdot \mathrm{kg}^{-1} \cdot \mathrm{min}^{-1}$ for girls, $83.0 \%$ of participants were classified as fit, including $86.3 \%$ of girls and $79.1 \%$ of boys, which was not statistically different, Chi-square (1) 2.3 , $p=0.354$. Boys were found to have significantly higher allometrically scaled $\mathrm{VO}_{2 \text { peak }}$ $(\mathrm{t}(92)=3.6, p=0.001)$ than girls. Further descriptive data regarding CRF and SHS exposure are provided in the Supplementary Materials S7.

\subsubsection{Physical Activity}

The mean level of self-reported physical activity (PA) is presented in Table 1 and the Supplementary Materials S2 and S3. No significant differences were observed between boys and girls for PA score $(\mathrm{t}(101)=1.7, p=0.099)$. Using a threshold score of 2.73 to classify children as active, $87.4 \%$ of children in the sample were classified as physically active. When split by sex, $95.7 \%$ of boys and $80.7 \%$ of girls were classified as physically active, which was statistically significant (Chi-square $(1)=5.2, p=0.023$ ). Further descriptive data regarding PA and SHS exposure are provided in the Supplementary Materials S8.

\subsubsection{Spirometry}

The mean spirometry (\%) values for the sample are shown in Table 1. For all four spirometry measures, mean values were below the predicted values for sex, age, height, and ethnicity (equivocal to $100 \%$ ) by $10.3-24.7 \%$, indicating lower than predicted spirometry across the sample. No significant differences were observed between the mean spirometry values for boys and girls (S2). Further descriptive data regarding spirometry and SHS exposure are provided in the Supplementary Materials S9. 


\subsubsection{Fractional Exhaled Nitric Oxide}

The range for FeNO measurements was high with a minimum value of $<5 \mathrm{ppb}$ (below the detection limit of $5 \mathrm{ppb}$ ) and a maximum of $147 \mathrm{ppb}$. The mean concentrations of FeNO are presented in Table 1 and the Supplementary Materials S2 and S3 and were not statistically different between boys and girls $(\mathrm{t}(100)=0.9, p=0.384)$. FeNO levels could be classified as low, intermediate, and high according to established thresholds [58]. Most children $(70.6 \%)$ had low levels ( $<20 \mathrm{ppb})$ of FeNO, $13.7 \%$ had intermediate levels (20-35 ppb), and $15.7 \%$ had high levels ( $>35 \mathrm{ppb}$ ). FeNO concentrations were not significantly different between children with diagnosed asthma $(24.4 \pm 12.7 \mathrm{ppb}, \mathrm{n}=9)$ and those without asthma $(20.9 \pm 23.7 \mathrm{ppb}),(\mathrm{t}(96)=-0.6, p=0.567)$. Further descriptive data regarding spirometry and SHS exposure are provided in the Supplementary Materials S10.

\subsubsection{Household Smoking Status}

Tobacco smoking only, by one or more members of the household, was reported in 35 households (33.7\%). In addition, three parents reported using e-cigarettes in addition to smoking tobacco $(2.9 \%)$, and parents from ten households reported using e-cigarettes only $(9.6 \%)$. Therefore, a total of $38(36.6 \%)$ households reported smoking tobacco. Neither smoking tobacco cigarettes nor using e-cigarettes was reported in 56 (53.8\%) households. Of the 38 participating households that reported tobacco smoking, ten $(26.3 \%)$ reported two people living in the home that smoked, with the remaining 28 households (73.7\%) reporting only one smoker living in the home. For tobacco smoking households, the mean total household cigarettes smoked per day was 16.6 (SD 14.2, range 60), with the majority of smoking parents/guardians reporting smoking 20 cigarettes or less per day.

Overall, $61.9 \%$ of households did not allow smoking anywhere in or around the house, $27.8 \%$ allowed smoking outside only, and $10.3 \%$ allowed smoking inside. Many parents from non-smoking households $(\mathrm{n}=60,90.9 \%)$ reported that smoking was not allowed anywhere at the home, not even outside, whilst six $(9.1 \%)$ parents from non-smoking households stated that smoking was allowed outside (by visiting family and friends). For smoking households, $24(63.2 \%)$ stated that smoking was allowed outside only, and $14(36.8 \%)$ reported that smoking was allowed inside. Out of the self-reported smoking households, $12.1 \%$ responded that smoking was allowed in the car, although seven parents failed to answer this question. Participant characteristics, split by household smoking status, are provided in the Supplementary Materials S3.

\subsubsection{Carbon Monoxide as a Measure of Second-Hand Tobacco Smoke Exposure}

Exhaled carbon monoxide (eCO) had a range of $7 \mathrm{ppm}$, with a low value of $0 \mathrm{ppm}$ (below the detection limit). Mean eCO was $1.8 \mathrm{ppm}$ and this was not significantly different between boys and girls $(\mathrm{t}(98)=-0.6, p=0.570)$. Although the mean $\mathrm{eCO}$ was higher for children from smoking households by $17.6 \%$, the finding was not significantly significant $(\mathrm{t}(98)=-2.3, p=0.214)$. Exhaled $\mathrm{CO}$ was not correlated with the square root transformed number of cigarettes smoked per day $(r=0.157, p=0.119)$. The concentration of eCO was highest for children from homes where smoking was permitted inside, followed by outside, then no smoking (S12), but the finding was not statistically significant (ANOVA $(2,97)=2.3$, $p=0.104)$.

\subsection{Association between Second-Hand Smoke Exposure and Children's Cardiorespiratory Fitness}

Table 2 shows the results of the unadjusted and adjusted multiple regression analyses run to predict allometrically scaled $\mathrm{VO}_{2 \text { peak }}\left(\mathrm{mL} \cdot \mathrm{kg}^{-0.53} \cdot \mathrm{min}^{-1}\right)$ from the number of cigarettes smoked per day (sqrt-cigarettes), controlling for sex, age, stature, maturation, PA, and $\operatorname{logEIMD}$. Sqrt-cigarettes was not a significant predictor in the unadjusted model $\left(R^{2}=0.036, F(1,91)=3.4, p=0.068\right.$; adjusted $\left.R^{2}=0.025\right)$. In the adjusted model, sqrt-cigarettes, sex, age, stature, and PA were significant predictors, whereas maturation and $\log$ EIMD were not. Overall, the adjusted model significantly predicted allometrically 
scaled $\mathrm{VO}_{2 \text { peak }}\left(\mathrm{R}^{2}=0.352, F(7,85)=6.6, p<0.001\right.$; adjusted $\left.\mathrm{R}^{2}=0.299\right)$, with a moderate $\mathrm{R}^{2}$, explaining $29.9 \%$ of the variance.

Table 2. Linear regression models examining association between the number of cigarettes smoked per day per household and allometrically scaled $\mathrm{VO}_{2 \text { peak }}\left(\mathrm{mL} \cdot \mathrm{kg}^{-0.53} \cdot \mathrm{min}^{-1}\right)$.

\begin{tabular}{|c|c|c|c|c|c|}
\hline \multirow{2}{*}{ Model and Predictor } & \multirow{2}{*}{$\begin{array}{l}\text { Unstandardised } \\
\text { Coefficient (B) }\end{array}$} & \multicolumn{2}{|c|}{ 95\% Confidence Interval } & \multirow{2}{*}{$\begin{array}{c}\text { Standard Error } \\
\text { of B }\end{array}$} & \multirow{2}{*}{ Significance } \\
\hline & & Lower Bound & Upper Bound & & \\
\hline \multicolumn{6}{|l|}{$\begin{array}{c}\text { Unadjusted model } \\
\left(\mathrm{R}^{2}=0.036, p=0.068, \mathrm{~F}=3.4\right)\end{array}$} \\
\hline Constant & 252.3 & 243.1 & 261.5 & 4.6 & $<0.001$ \\
\hline Sqrt-cigarettes & -3.7 & -7.6 & 0.3 & 2.0 & 0.068 \\
\hline \multirow{2}{*}{\multicolumn{6}{|c|}{$\begin{array}{c}\text { Adjusted model } \\
\left(\mathrm{R}^{2}=0.352, p<0.001, \mathrm{~F}=6.6\right)\end{array}$}} \\
\hline & & & & & \\
\hline Constant & -113.7 & -331.9 & 104.5 & 109.7 & 0.303 \\
\hline Sqrt-cigarettes & -3.8 & -7.3 & -0.4 & 1.7 & 0.030 \\
\hline Sex & -26.2 & -49.0 & -3.4 & 11.5 & 0.025 \\
\hline Age (years) & 12.2 & 0.4 & 23.9 & 5.9 & 0.042 \\
\hline Stature $(\mathrm{cm})$ & 1.3 & 0.1 & 2.5 & 0.6 & 0.036 \\
\hline Maturation (years to PHV) & 0.1 & -12.4 & 12.4 & 6.2 & 0.998 \\
\hline Physical activity & 15.4 & 6.0 & 24.8 & 4.7 & 0.002 \\
\hline LogEIMD & 5.2 & -5.7 & 16.0 & 5.5 & 0.347 \\
\hline
\end{tabular}

Abbreviations: Sqrt-cigarettes = the square root of the total number of cigarettes smoked per household per day; PHV = peak height velocity; $\log$ EIMD = log-transformed English Indices of Multiple Deprivation (based on household postcode).

A follow-up linear regression analysis was undertaken in a subsample of children living in smoking households $(\mathrm{n}=38)$ to explore the impact of whether indoor smoking was permitted or whether smoking was permitted outdoors only $(n=24)$ in the household. Table 3 shows the results of the unadjusted and adjusted multiple regression analyses run to predict allometrically scaled $\mathrm{VO}_{2 \text { peak }}\left(\mathrm{mL} \cdot \mathrm{kg}^{-0.53} \cdot \mathrm{min}^{-1}\right)$ from where smoking was permitted (indoors or outdoors only) in smoking homes, controlling for sex, age, stature, maturation, PA, and logEIMD. Smoking indoors was not a significant predictor in the unadjusted model $\left(\mathrm{R}^{2}=0.011, p=0.548, F(1,35)=0.4\right.$; adjusted $\left.\mathrm{R}^{2}=-0.018\right)$. In the adjusted model, only PA was a significant predictor, whereas smoking indoors, sex, age, stature, maturation, and logEIMD were not. Overall, this adjusted model did not significantly predict allometrically scaled $\mathrm{VO}_{2 \text { peak }}\left(\mathrm{R}^{2}=0.297, p=0.153, F(7,35)=1.7\right.$; adjusted $R^{2}=0.121$ ).

\subsection{Association between Second-Hand Smoke Exposure and Children's Physical Activity}

Table 4 shows the results of the unadjusted and adjusted multiple regression analyses to predict physical activity from the number of cigarettes smoked per day (sqrt-cigarettes), controlling for sex, age, BMI, maturation, and logEIMD. Sqrt-cigarettes was not a significant predictor in the unadjusted model $\left(\mathrm{R}^{2}<0.001, F(1,100)=0.05, p=0.826\right.$; adjusted $\left.\mathrm{R}^{2}=-0.010\right)$. In the adjusted model, there were no statistically significant predictors of PA. Overall, the adjusted model did not predict $\mathrm{PA}\left(\mathrm{R}^{2}=0.089, F(5,96)=1.9, p=0.104\right.$; adjusted $\mathrm{R}^{2}=0.042$ ).

\subsection{Association between Second-Hand Smoke Exposure and Markers of Respiratory Health in Children}

Several multiple regressions were run to predict $\mathrm{FEV}_{1} \%, \mathrm{FVC} \%, \mathrm{PER} \%$, and $\mathrm{FER}$ from the number of cigarettes smoked per day (sqrt-cigarettes), mass, diagnosed asthma, and logEIMD. See Table 5 for the summary of the unadjusted and adjusted models for each respiratory measure (full details for each model can be found in the Supplementary Materials S11). 
Table 3. Linear regression models examining association between indoor and outdoor smoking and allometrically scaled $\mathrm{VO}_{2 \text { peak }}\left(\mathrm{mL} \cdot \mathrm{kg}^{-0.53} \cdot \mathrm{min}^{-1}\right)$ among children from smoking households $(\mathrm{n}=38)$.

\begin{tabular}{|c|c|c|c|c|c|}
\hline \multirow{2}{*}{ Model and Predictor } & \multirow{2}{*}{$\begin{array}{l}\text { Unstandardised } \\
\text { Coefficient (B) }\end{array}$} & \multicolumn{2}{|c|}{ 95\% Confidence Interval } & \multirow{2}{*}{$\begin{array}{c}\text { Standard Error } \\
\text { of B }\end{array}$} & \multirow{2}{*}{ Significance } \\
\hline & & Lower Bound & Upper Bound & & \\
\hline \multicolumn{6}{|l|}{$\begin{array}{c}\text { Unadjusted model } \\
\left(\mathrm{R}^{2}=0.011, p=0.548, \mathrm{~F}=0.4\right)\end{array}$} \\
\hline Constant & 241.3 & 226.4 & 256.3 & 7.4 & $<0.001$ \\
\hline Smoke indoors & -7.4 & -32.3 & 17.5 & 12.2 & 0.548 \\
\hline \multicolumn{6}{|l|}{$\begin{array}{c}\text { Adjusted model } \\
\left(\mathrm{R}^{2}=0.297, p=0.153, \mathrm{~F}=1.7\right)\end{array}$} \\
\hline Constant & 136.3 & -318.4 & 591.0 & 222.0 & 0.544 \\
\hline Smoking indoors & -17.0 & -41.2 & 7.1 & 11.8 & 0.159 \\
\hline Sex & -26.3 & -62.0 & 9.3 & 17.4 & 0.142 \\
\hline Age (years) & -0.7 & -24.2 & 22.8 & 11.5 & 0.951 \\
\hline Stature $(\mathrm{cm})$ & 0.6 & -1.9 & 3.2 & 1.2 & 0.611 \\
\hline Maturation (years to PHV) & 5.6 & -14.4 & 25.7 & 9.8 & 0.570 \\
\hline Physical activity & 20.4 & 4.7 & 36.2 & 7.7 & 0.013 \\
\hline LogEIMD & -7.5 & -32.0 & 17.0 & 12.0 & 0.538 \\
\hline
\end{tabular}

Abbreviations: PHV = peak height velocity; $\log E I M D=$ log-transformed English Indices of Multiple Deprivation (based on household postcode). Bold for statistically significant findings $(p<0.05)$.

Table 4. Linear regression models examining association between smoking exposure and self-reported physical activity.

\begin{tabular}{|c|c|c|c|c|c|}
\hline \multirow{2}{*}{ Model and Predictor } & \multirow{2}{*}{$\begin{array}{l}\text { Unstandardised } \\
\text { Coefficient (B) }\end{array}$} & \multicolumn{2}{|c|}{$95 \% \mathrm{CI}$} & \multirow{2}{*}{$\begin{array}{c}\text { Standard Error } \\
\text { of B }\end{array}$} & \multirow{2}{*}{ Significance } \\
\hline & & Lower Bound & Upper Bound & & \\
\hline \multicolumn{6}{|l|}{$\begin{array}{c}\text { Unadjusted model } \\
\left(\mathrm{R}^{2}<0.001, p=0.826, F=0.05\right)\end{array}$} \\
\hline Constant & 3.64 & 3.47 & 3.81 & 0.08 & $<0.001$ \\
\hline Sqrt-cigarettes & 0.01 & -0.07 & 0.08 & 0.04 & 0.826 \\
\hline \multirow{2}{*}{\multicolumn{6}{|c|}{$\begin{array}{c}\text { Adjusted model } \\
\left(\mathrm{R}^{2}=0.089, p=0.104, F=1.9\right)\end{array}$}} \\
\hline & & & & & \\
\hline Constant & 6.54 & 3.05 & 10.03 & 1.76 & $<0.001$ \\
\hline Sqrt-cigarettes & 0.03 & -0.05 & 0.11 & 0.04 & 0.456 \\
\hline Sex & -0.29 & -0.80 & 0.21 & 0.25 & 0.255 \\
\hline Age (years) & -0.21 & -0.47 & 0.04 & 0.13 & 0.100 \\
\hline BMI $\left(\mathrm{kg} \cdot \mathrm{m}^{-2}\right)$ & -0.03 & -0.07 & 0.01 & 0.02 & 0.104 \\
\hline Maturation (years to PHV) & 0.05 & -0.22 & 0.31 & 0.13 & 0.732 \\
\hline LogEIMD & 0.04 & -0.20 & 0.28 & 0.12 & 0.751 \\
\hline
\end{tabular}

Abbreviations: Sqrt-cigarettes = the square root of the total number of cigarettes smoked per household per day; BMI = body mass index; PHV = peak height velocity; logEIMD = log-transformed English Indices of Multiple Deprivation (based on household postcode). Bold for statistically significant findings $(p<0.05)$.

For $\mathrm{FEV}_{1} \%$, sqrt-cigarettes was not a significant predictor in the unadjusted model $\left(\mathrm{R}^{2}<0.001, F(1,101)=0.3, p=0.864 ;\right.$ adjusted $\left.\mathrm{R}^{2}=-0.010\right)$. In the adjusted model, logEIMD was a significant predictor but sqrt-cigarettes, mass, and asthma were not. Overall, the adjusted model significantly predicted FEV1 $\%\left(R^{2}=0.138, F(4,100)=3.9, p=0.005\right.$; adjusted $\left.\mathrm{R}^{2}=0.103\right)$, although only $10.3 \%$ of the variation was explained by the model.

For FVC\%, sqrt-cigarettes was not a significant predictor in the unadjusted model $\left(R^{2}=0.013, F(1,101)=1.4, p=0.247\right.$; adjusted $\left.R^{2}=0.003\right)$. In the adjusted model, logEIMD was a significant predictor but sqrt-cigarettes, mass, and asthma were not. Overall, the adjusted model significantly predicted FVC $\%\left(R^{2}=0.135, F(4,98)=3.8, p=0.006\right.$; adjusted $\mathrm{R}^{2}=0.099$ ), although only $9.9 \%$ of the variance was explained by the model.

For $\mathrm{PEF} \%$, sqrt-cigarettes was not a significant predictor in the unadjusted model $\left(R^{2}=0.002, F(1,100)=0.2, p=0.659\right.$; adjusted $\left.R^{2}=-0.008\right)$. In the adjusted model, none of the predictors were statistically significant. Overall, the adjusted model did not significantly predict PEF\% $\left(R^{2}=0.064, F(4,97)=1.7, p=0.166\right.$; adjusted $\left.R^{2}=0.025\right)$. 
For FER (FEV1/FVC), sqrt-cigarettes was not a significant predictor in the unadjusted model $\left(\mathrm{R}^{2}=0.015, F(1,99)=1.5, p=0.227\right.$; adjusted $\left.\mathrm{R}^{2}=0.005\right)$. In the adjusted model, none of the predictors were statistically significant. Overall, the adjusted model did not significantly predict FER $\left(\mathrm{R}^{2}=0.030, F(4,96)=0.7, p=0.561\right.$; adjusted $\left.\mathrm{R}^{2}=-0.010\right)$.

A multiple regression was run to predict logFeNO from the number of cigarettes smoked per day (sqrt-cigarettes), sex, age, stature, mass, diagnosed asthma, and logEIMD. Sqrt-cigarettes was not a significant predictor in the unadjusted model $\left(\mathrm{R}^{2}=0.001\right.$, $F(1,95)=0.09, p=0.760$; adjusted $\left.\mathrm{R}^{2}=-0.010\right)$. In the adjusted model, no predictors were statistically significant, and the model was not statistically significant overall $\left(\mathrm{R}^{2}=0.050\right.$, $F(7,89)=0.7, p=0.701$; adjusted $\left.\mathrm{R}^{2}=-0.025\right)$.

Table 5. Summary of spirometry and FeNO linear regression models.

\begin{tabular}{|c|c|c|c|c|c|c|c|}
\hline \multirow[b]{2}{*}{ Model } & \multirow{2}{*}{$\begin{array}{c}\text { Model } \\
\mathbf{R}^{2}\end{array}$} & \multirow{2}{*}{$\begin{array}{c}\text { Model } \\
\text { Significance, } p\end{array}$} & \multirow{2}{*}{$\begin{array}{l}\text { Unstandardised } \\
\text { Coefficient (B) for } \\
\text { Sqrt-Cigarettes }\end{array}$} & \multicolumn{2}{|c|}{ 95\% Confidence Interval } & \multirow{2}{*}{$\begin{array}{l}\text { Standard } \\
\text { Error of B }\end{array}$} & \multirow{2}{*}{$\begin{array}{l}\text { Significance } \\
\text { of } B, p\end{array}$} \\
\hline & & & & $\begin{array}{l}\text { Lower } \\
\text { Bound }\end{array}$ & $\begin{array}{l}\text { Upper } \\
\text { Bound }\end{array}$ & & \\
\hline $\begin{array}{c}\mathrm{FEV}_{1} \% \\
\text { unadjusted }\end{array}$ & $<0.001$ & 0.864 & -0.2 & -2.0 & 1.7 & 0.9 & 0.864 \\
\hline $\begin{array}{l}\mathrm{FEV}_{1} \% \\
\text { adjusted }\end{array}$ & 0.138 & 0.005 & 0.4 & -1.4 & 2.2 & 0.9 & 0.660 \\
\hline $\begin{array}{c}\text { FVC\% } \\
\text { unadjusted }\end{array}$ & 0.013 & 0.247 & -1.2 & -3.3 & 0.9 & 1.1 & 0.247 \\
\hline $\begin{array}{c}\text { FVC\% } \\
\text { adjusted }\end{array}$ & 0.135 & 0.006 & -0.7 & -2.8 & 1.3 & 1.0 & 0.494 \\
\hline $\begin{array}{c}\mathrm{PEF} \% \\
\text { unadjusted }\end{array}$ & 0.002 & 0.659 & -0.6 & -2.7 & 1.6 & 1.1 & 0.608 \\
\hline $\begin{array}{c}\text { PEF\% } \\
\text { adjusted }\end{array}$ & 0.064 & 0.166 & 0.0 & -2.2 & 2.1 & 1.1 & 0.965 \\
\hline $\begin{array}{c}\text { FER } \\
\text { unadjusted }\end{array}$ & 0.015 & 0.227 & 0.6 & -0.4 & 1.7 & 0.5 & 0.227 \\
\hline FER adjusted & 0.030 & 0.561 & 0.7 & -0.4 & 1.8 & 0.5 & 0.204 \\
\hline $\begin{array}{c}\text { FeNO } \\
\text { unadjusted }\end{array}$ & 0.001 & 0.760 & -0.01 & -0.09 & 0.07 & 0.04 & 0.760 \\
\hline $\begin{array}{c}\text { FeNO } \\
\text { adjusted }\end{array}$ & 0.050 & 0.701 & -0.01 & -0.10 & 0.08 & 0.04 & 0.818 \\
\hline
\end{tabular}

Abbreviations: Sqrt-cigarettes = the square root of the total number of cigarettes smoked per household per day; $\mathrm{FEV}_{1}=$ forced expiratory volume in $1 \mathrm{~s} ; \mathrm{FVC}=$ forced vital capacity; $\mathrm{PEF}=$ peak expiratory flow; FER = forced expiratory ratio $\left(\mathrm{FEV}_{1} / \mathrm{FVC}\right) ; \mathrm{FeNO}=\ln$ fractional exhaled nitric oxide. $\mathrm{FEV}_{1}, \mathrm{FVC}$, and PEF expressed as percentages of predicted for sex, age, height, and ethnicity. $\mathrm{FEV}_{1} \%, \mathrm{FVC} \%$, $\mathrm{PEF} \%$, and FER models adjusted for mass, asthma diagnosis, and EIMD. FeNO models adjusted for sex, decimal age, mass, stature, asthma diagnosis, and EIMD.

\section{Discussion}

Our study demonstrates that second-hand smoke exposure, as measured by the number of cigarettes smoked per day within the household, is negatively associated with children's CRF, but no significant associations were observed for PA or respiratory measures.

\subsection{Household Smoking}

Over one third (36.6\%) of participants lived with a family member that smoked tobacco, which is significantly less than the findings of McGee et al. [33], who found $57.3 \%$ of children from the same region to have a family member that smoked. However, the current study was concerned with family members that lived with the participants and smoked. While smoking prevalence has also declined in the UK since 2015 [30], presently, $14.1 \%$ of adults are current smokers nationally, with smoking more common among adults in routine and manual occupations [30] with low education [79] or low 
SES $[32,80]$. The findings of the present study support the association between smoking and SES as low parental education and household deprivation were significantly associated with household smoking (see Supplementary Materials S5). Although household smoking was assessed through parent/guardian self-report, the smoking prevalence findings are similar to a study by Jarvis and Feyerabend [31], who used salivary cotinine analysis and found $31.5 \%$ of children in England to be exposed to SHS.

Exhaled carbon monoxide (eCO) was not found to be significantly different between children from smoking and non-smoking homes, although mean eCO was $17.6 \%$ higher for children from smoking homes. Exhaled $\mathrm{CO}$ was also not significantly correlated with the number of cigarettes smoked per day. There are several explanations for this finding, including the low sensitivity of eCO when predicting SHS exposure in children found in previous research [73], the age-related ability to perform the physically demanding test, and exposure to other environmental sources of $\mathrm{CO}$ prior to the test, including the road microenvironment [81], industry, and solid fuel burning [82]. Cotinine, a metabolite of nicotine, can be found in the hair, saliva, urine, and blood of individuals exposed to SHS [83-85] and is an alternative measure regularly used in research to determine recent active and passive smoking [86,87]. Cotinine is a sensitive and specific indicator of recent exposure to nicotine and is accepted as the best available biomarker of exposure to SHS [31]. Exhaled $\mathrm{CO}$ was selected as a method for establishing tobacco smoke exposure due to the low-participant burden, low cost, ease of interpretation, and instant results. However, as eCO has not shown to be an effective determinant of SHS in children, future research should seek to use salivary cotinine analysis to determine recent tobacco smoke exposure.

\subsection{Cardiorespiratory Fitness and Physical Activity Levels}

As most of the previous research regarding CRF with children expresses fitness as $\mathrm{mL} \cdot \mathrm{kg}^{-1} \cdot \mathrm{min}^{-1}$, it is useful to note ratio scaled $\mathrm{VO}_{2 \text { peak }}$ in order to compare fitness profiles of our sample with those of previous relevant literature. The mean ratio scaled $\mathrm{VO}_{2 \text { peak }}$ for boys $\left(47.7 \mathrm{~mL} \cdot \mathrm{kg}^{-1} \cdot \mathrm{min}^{-1}\right)$ and girls $\left(42.7 \mathrm{~mL} \cdot \mathrm{kg}^{-1} \cdot \mathrm{min}^{-1}\right)$ reported in our sample is in line with previous research with similar aged children from Northwest England. A study by Boddy et al. [66] which used a similar laboratory-based protocol to measure $\mathrm{CRF}$, found means of 46.7 and $40.2 \mathrm{~mL} \cdot \mathrm{kg}^{-1} \cdot \mathrm{min}$ for boys and girls, respectively. CRF levels in children from Northwest England have been in decline in recent years [6,7], although the similarity of the results of the present study with that of Boddy et al. [66] suggests the trend may have stabilised. Using established international thresholds of ratio scaled $\mathrm{VO}_{2 \text { peak }}$ values [71], $86.3 \%$ of girls and $79.1 \%$ of boys in the present study reached the threshold for healthy 'fitness', with the remaining children below the threshold and therefore raising a 'clinical red flag' and at risk of cardiovascular disease. For comparison, $78 \%$ of boys and $83 \%$ of girls from 30 countries met the standards for healthy CRF [88], although CRF was estimated based on $20 \mathrm{~m}$ shuttle run test performance. The high levels of fitness observed in our sample could be explained by high levels of participation in physical activity [3]. Indeed, the proportion of children in the present study classified as 'active' according to PAQ-C thresholds [89] was $95.7 \%$ for boys and $80.7 \%$ for girls. The Benitez-Porres et al. [89] thresholds suggest the use of a cut-point of 2.73 on the PAQ$\mathrm{C}$ to discriminate $>60 \mathrm{~min}$ of MVPA per day in children. Therefore, while not directly comparable due to different survey instruments, the proportion of children in the present study meeting the daily recommendation of $60 \mathrm{~min}$ of PA per day is far higher than the national average in England of $51 \%$ of boys and $43 \%$ of girls [13]. The mean PA score was 3.6 (SD 0.7), which is very similar to that found by Noonan et al. [90], also with children from deprived neighbourhoods of Northwest England and using the PAQ-C (3.5, SD 0.7). While the self-reported PA data should be interpreted with caution as surveys are subject to recall and desirability bias, the relatively high proportion of children classified as fit and physically active in the present study indicates that intervention efforts should focus on preventing a decline in these important health markers into adolescence and adulthood. 


\subsection{Association of Second-Hand Smoke Exposure with Cardiorespiratory Fitness}

The present study examined the association of smoking exposure with children's cardiorespiratory fitness using allometrically scaled $\mathrm{VO}_{2 \text { peak }}$. As noted above, most research to date has expressed CRF as $\mathrm{VO}_{2 \text { peak }}$ ratio scaled for mass $\left(\mathrm{mL} \cdot \mathrm{kg}^{-1} \cdot \mathrm{min}^{-1}\right)$, but expressing CRF in this way over-scales for mass and leads to spurious correlations with other health-related outcomes [70]. Recently, allometric scaling has been suggested [70] and is being used increasingly in research with youth [91,92]. Mass exponents can be generated for a sample population via log-linear regression (see methods). Mass exponents are sample-specific, and the generated exponent of the present study (0.526) is within the range of those found in previous studies $[70,93,94]$.

Following adjustments for sex, age, stature, maturation, PA, and deprivation, the number of cigarettes smoked per day by the household was found to be negatively associated with children's allometrically scaled $\mathrm{VO}_{2 \text { peak }}$. A follow-up analysis was conducted to explore the effect of smoking indoors compared to outdoors only on children from smoking households' CRF. Although smoking indoors was not found to be a statistically significant predictor within the model, the negative $B$ coefficient indicates a negative relationship between smoking indoors and children's CRF. As the number of parents that reported smoking indoors was low $(n=14)$, further research with a larger sample size is warranted given that smoking indoors in the household is likely to be more harmful to the child than smoking being permitted outdoors only. Although no prior research has yet examined the impact of SHS exposure on children's laboratory measured $\mathrm{VO}_{2 \text { peak }}$, the results are in line with Magnússon et al. [38], who have found children's CRF (measured by maximal cycle ergometer test) to be significantly reduced for those with smoking parents. Kaymaz et al. [40] have also shown that children exposed to parental smoking have reduced performance on the six-minute walk test. The mechanism by which SHS exposure reduces $\mathrm{VO}_{2 \text { peak }}$ cannot be determined from the present study, but key components of tobacco smoke such as $\mathrm{CO}$ and particulate matter have each been shown to individually impact CRF. CO, which has a higher affinity for haemoglobin than oxygen, acutely decreases aerobic capacity through hypoxaemia of peripheral tissues due to haemoglobin-bound $\mathrm{CO}$ [37]. Particulate matter exposure causes systemic inflammation and increased oxidative stress, leading to impaired cardiovascular, immune, and pulmonary function [95] and reduced exercise performance [96]. A vast body of research relating to the detrimental effects of tobacco smoke exposure has emerged since the pioneering work of Doll and Hill in the 1950s [97,98], but recently, research in the emerging field of epigenetics has observed the transgenerational effects of tobacco smoke, whereby paternal and maternal smoking results in changes in DNA methylation for the offspring that persist many years after exposure $[99,100]$.

It is possible that there is a dose-response relationship between SHS exposure and CRF, as dose-response relationships have been observed between SHS exposure and a number of other health-related variables including birthweight, sudden infant death syndrome, cognitive and behavioural problems, respiratory issues, childhood obesity, and increased blood pressure 18 years post-exposure [101-103]. In the present study, the range for the number of cigarettes smoked per household per day was large at 65 , and the data were positively skewed as the majority of participants were from non-smoking households. Most of the participating smoking parents/guardians smoked 20 or less cigarettes per day, with very few households smoking more than 20 . Future work should aim to include more children from heavily smoking households, either through a larger sample size or targeted recruitment. Additionally, as discussed above, cotinine testing has a very high sensitivity and specificity for SHS exposure and might enable better quantification of a potential dose-response relationship between SHS and CRF in children.

Children may be more susceptible to the effects of SHS due to their increased respiratory rates and immature and developing organs [24]. Furthermore, children may be especially vulnerable if exposed prenatally $[103,104]$. Although in utero exposure was not within the scope of this study, there is a need for longitudinal studies to examine the impact of SHS exposure across the life-course. It would be of value to understand whether the 
apparent detrimental effects of SHS seen in children's fitness in the present study track into late adolescence and adulthood, and whether the effects persist even after SHS exposure has ceased.

\subsection{Association of Second-Hand Smoke Exposure with Physical Activity}

Despite the negative association between SHS exposure and CRF, we found no relationship between the number of cigarettes smoked in the home and children's self-reported PA. These findings are encouraging as results indicate SHS exposure is not impacting children of smoking households' engagement in PA, which has beneficial implications for subsequent disease risk. Nevertheless, recent qualitative research indicates that household smoking status may influence children's perceptions, barriers, facilitators, and beliefs surrounding PA and exercise [43]. Children from smoking households rated metabolically demanding activities such as running as more difficult than children from non-smoking homes, and indicated a preference for less strenuous activities [43]. The same study also showed that children from non-smoking households demonstrated greater awareness of PA guidelines, referred to extrinsic motivators of PA and the health benefits of fitness, and had considerations for the future self in terms of PA and fitness. As per the Youth Physical Activity Promotion Model [105], personal demographics (age, gender, ethnicity, SES), enabling factors (fitness, skills, access, environment), reinforcing factors (family, peer, and couch influence), and predisposing factors (perceived competence, self-efficacy, enjoyment, beliefs, attitudes) can all influence PA in children. PA is an established determinant of CRF [74], and an active child is more likely to be fit and healthy [106,107]. However, as the reverse causation hypothesis for obesity and PA implies a positive feedback loop [108], low CRF may similarly discourage participation in PA, further decreasing CRF in the inactive child.

\subsection{Markers of Respiratory Health}

\subsubsection{Association between Second-Hand Smoke Exposure and Spirometry Outcomes}

Across the sample, and for all measures (FEV1\%, FVC\%, PEF\%, FER), spirometry values were below the predicted values based on children's age, sex, stature, and ethnicity by $10.3-24.7 \%$, suggesting lower than average lung function across the whole sample. Participant cooperation, effort, experience, and practice are important factors when undertaking spirometry testing, and children require encouragement and practice to successfully undertake the forced manoeuvres required for a valid test [109]. Despite the high levels of encouragement from the trained research team, some children may not have cooperated fully and therefore achieved sub-optimal spirometry performance.

Linear regression analysis showed that the number of cigarettes smoked per day was not a significant predictor of $\mathrm{FEV}_{1} \%, \mathrm{FVC} \%, \mathrm{PEF} \%$, or $\mathrm{FER}$, following adjustments for mass, asthma, and deprivation. For the $\mathrm{FEV}_{1} \%$ and FVC $\%$ models, deprivation (EIMD) was the only statistically significant predictor, indicating higher deprivation is associated with decreased lung function. All participants' postcodes were within the lowest four EIMD deciles (high and medium deprivation), and $85.5 \%$ of participant postcodes were within the lowest two deciles. Socioeconomic status is an established determinant of lung function [78,110], and the low spirometry values across the sample may be reflecting the low SES of the sample. Indoor and outdoor air quality are associated with respiratory health [111], and living near major roadways is associated with decreased FVC and increased FeNO [112]. Poverty and environmental exposures may explain the ethnic differences for spirometry performance observed within the literature [113]. In the present study, spirometry values were normalised by a factor of 0.9 for black children and 0.95 for children of other ethnicities as per Korotzer et al. [62].

Our results contrast with research that has demonstrated a negative association between SHS exposure and lung function. A large amount of research has shown SHS exposure to be detrimental to lung function [114-118], with the effects of early life exposure observed decades later [25]. Li et al. [117] suggest that results demonstrating the impact 
of SHS on children's lung health should be interpreted considering in utero exposure. Data on in utero exposure were not collected in the present study, but previous research indicates that in utero exposure to tobacco smoke is especially detrimental to lung function (reduced expiratory flow, mid-expiratory flow, forced vital capacity, fractional exchange ratio), likely due to the effects of SHS on development and growth $[118,119]$. Future work could incorporate data on in utero exposures, as well as monitoring lung function during and after maximal exercise, and may reveal exercise-related variations in lung function for children exposed to tobacco smoke both in utero and ex utero.

\subsubsection{Association between Second-Hand Smoke Exposure and Fractional Exhaled Nitric Oxide}

The range of FeNO concentrations in our sample was large (147 ppb), and most children $(70.6 \%)$ had low levels (<20 ppb) of FeNO, 13.7\% had intermediate levels (20-35 ppb), and $15.7 \%$ had high levels ( $>35 \mathrm{ppb}$ ). High levels of FeNO indicate eosinophilic airway inflammation, which itself may indicate asthma [58]. Although the FeNO concentrations of diagnosed asthmatics $(n=9)$ were slightly elevated compared to non-diagnosed asthmatics, this was not statistically significant. However, this may indicate that asthma was successfully being treated in those diagnosed [120]. FeNO concentrations can also be influenced by recent ingestion of food and drink, foods high in nitrates [121], rhinovirus infection, allergic rhinitis [122], and genetics [123].

Nitric oxide (NO) is important for metabolic regulation during exercise as a modulator of blood flow, regulating muscle contraction and influencing muscle glucose uptake [124]. Nitric oxide bioavailability is associated with increased exercise performance in untrained individuals, including a reduced $\mathrm{O}_{2}$ cost of low-intensity exercise and improved exercise time to exhaustion $[125,126]$, with exercise training elevating NO bioavailability [124]. SHS exposure may reduce CRF through the action of particulate matter on the bioavailability of NO, an important and potent vasodilator. However, after adjusting for sex, age, mass, stature, asthma, and deprivation, no association was found between smoking exposure and FeNO. None of the predictors in the adjusted model, including the number of cigarettes, sex, age, mass, stature, asthma, or EIMD, were significant in the model for FeNO. For active and passive smokers, the association between FeNO and airway inflammation is complicated. Although FeNO is increased in untreated adult asthmatics who smoke, FeNO concentrations are generally reduced in smokers and individuals exposed to SHS $[127,128]$. Increasing cotinine levels have been found to be associated with a progressive reduction in FeNO and an increase in blood eosinophil count in healthy individuals aged 6-80 years [129]. The mechanism by which tobacco smoke reduces FeNO is likely to be through the reduction in the enzymatic activity of nitric oxide synthase, in combination with superoxides (found in tobacco smoke in high concentrations), which react with $\mathrm{NO}$ to produce active nitrogen species [130]. Therefore, FeNO is reduced in active and passive smokers due to the suppression of production and elimination of NO. Future work should look to understand how FeNO changes in exercising children exposed to SHS. As NO is important for several biological and exercise-related pathways, the reduction of NO in SHS-exposed individuals may be significant in relation to CRF and warrants further research in paediatric populations.

\subsection{Strengths and Limitations}

This study is the first to examine the association between SHS exposure and children's $\mathrm{CRF}$, PA, and respiratory measures including FeNO and spirometry. CRF was determined by direct measurement of $\mathrm{VO}_{2 \text { peak }}$ through a laboratory-based treadmill protocol, which is the 'gold standard' measure of young people's CRF [70]. The sample population of this study are representative of 9-11-year-old children from deprived areas in Merseyside, UK, providing valuable information relating to SHS exposure and health markers for this demographic. The study nonetheless includes some limitations. Due to the high research saturation of local primary schools and the contentious nature of the project, the study achieved a relatively small sample size of 104 participants ( $3 \%$ participation rate), including 
38 children from smoking households. Furthermore, the relatively high proportion of children classified as fit in the present study may also be due to bias, where predominantly active children with confidence in their abilities volunteer to participate in the study. While the sample population of this study are representative children from deprived areas of the UK, future research should aim to include children from a greater variety of SES backgrounds, age groups, and geographic locations. Household smoking status and child PA were measured via surveys, which are subject to recall errors and desirability bias and may have led to under/over estimation of these behaviours. Device-based measurement of PA could have provided further information regarding PA behaviour, a key determinant of CRF. Furthermore, while the use of eCO as a method of SHS exposure quantification was selected due to the low-participant burden, low cost, ease of interpretation, and instant results, future studies should seek to use cotinine testing to better determine SHS exposure.

\section{Conclusions}

To the authors' knowledge, this is the first study to examine the association between SHS exposure and children's CRF, PA, and respiratory health. An important finding was that the number of cigarettes smoked per day in each household was a significant and negative predictor of allometrically scaled $\mathrm{VO}_{2 \text { peak }}\left(\mathrm{mL} \cdot \mathrm{kg}^{-0.53} \cdot \mathrm{min}^{-1}\right)$. No associations were found between SHS exposure and physical activity or between SHS exposure and spirometry and FeNO respiratory health measures. CRF is a global measure of health, and these findings are indicative of lower health status in children from smoking households. Low CRF is associated with a plethora of negative health outcomes and as fitness tracks into adulthood, efforts should be made to improve CRF during childhood. Reducing SHS exposure may be an effective measure for improving CRF in children from smoking households, and a potential avenue for intervention aiming to improve CRF in low SES populations. Future work should aim to incorporate cotinine testing and the use of a larger sample of children exposed to SHS to determine and quantify the potential doseresponse relationship between SHS and CRF. Additionally, research is required to determine the mechanism by which SHS exposure is detrimental to children's CRF, and the use of longitudinal research is required to uncover long-term impacts of SHS exposure and children's CRF.

Supplementary Materials: The following are available online at https:/ /www.mdpi.com/article/ 10.3390/ijerph182111445/s1. S1. Research Timeline; S2. Descriptive statistics by sex; S3. Descriptive statistics by household smoking status and sex; $\mathrm{S} 4$. Linear regression for absolute $\mathrm{VO}_{2 \text { peak }}$; S5. Household smoking and socioeconomic status; S6. Household smoking and weight status; S7. Supplementary data for cardiorespiratory fitness and second-hand smoke exposure; S8. Supplementary data for physical activity and second-hand smoke exposure; S9. Supplementary data for spirometry and household smoking status; S10. Supplementary data for fractional exhaled nitric oxide and second-hand smoke exposure; S11. Supplementary data for linear regressions for spirometry measures; S12. Exhaled carbon monoxide and household smoking.

Author Contributions: Conceptualization, M.P., L.F., G.W. and I.G.; methodology, M.P., L.F., G.W., J.D. and I.G.; investigation, M.P.; data curation, M.P.; writing-original draft preparation, M.P.; writing—review and editing, M.P., L.F., G.W., J.D. and I.G.; supervision, I.G., L.F., G.W. and J.D.; project administration, M.P., I.G., G.W. and L.F. All authors have read and agreed to the published version of the manuscript.

Funding: This research was funded by the Liverpool John Moores University FREE PhD Studentship Fund.

Institutional Review Board Statement: The study was conducted according to the guidelines of the Declaration of Helsinki and approved by the Institutional Review Board (or Ethics Committee) of Liverpool John Moores University (Ref: 16/PBH/001, 2 March 2017).

Informed Consent Statement: Informed consent was obtained from all subjects involved in the study.

Data Availability Statement: The data in this study are available upon reasonable request from the corresponding author. The data are not publicly available due to privacy and ethical considerations. 
Acknowledgments: We would like to thank the schools, children, and families that participated in this research.

Conflicts of Interest: The authors declare no conflict of interest. The funders had no role in the design of the study; in the collection, analyses, or interpretation of data; in the writing of the manuscript, or in the decision to publish the results.

\section{References}

1. Lee, D.; Artero, E.G.; Sui, X.; Blair, S.N. Review: Mortality Trends in the General Population: The Importance of Cardiorespiratory Fitness. J. Psychopharmacol. 2010, 24 (Suppl. 4), 27-35. [CrossRef]

2. $\quad$ Lang, J.J.; Tomkinson, G.R.; Janssen, I.; Ruiz, J.R.; Ortega, F.B.; Léger, L.; Tremblay, M.S. Making a Case for Cardiorespiratory Fitness Surveillance among Children and Youth. Exerc. Sport Sci. Rev. 2018, 46, 66-75. [CrossRef] [PubMed]

3. Zaqout, M.; Vyncke, K.; Moreno, L.A.; De Miguel-Etayo, P.; Lauria, F.; Molnar, D.; Lissner, L.; Hunsberger, M.; Veidebaum, T.; Tornaritis, M.; et al. Determinant Factors of Physical Fitness in European Children. Int. J. Public Health 2016, 61, 573-582. [CrossRef]

4. $\quad$ Raghuveer, G.; Hartz, J.; Lubans, D.; Takken, T.; Wiltz, J.; Perak, A.; Baker-Smith, C.; Mietus-Snyder, M.; Pietris, N.; Edwards, N. Cardiorespiratory Fitness in Youth: An Important Marker of Health: A Scientific Statement From the American Heart Association. Circulation 2020, 142, e101-e118. [CrossRef] [PubMed]

5. Tomkinson, G.R.; Lang, J.J.; Tremblay, M.S. Temporal Trends in the Cardiorespiratory Fitness of Children and Adolescents Representing 19 High-Income and Upper Middle-Income Countries between 1981 and 2014. Br. J. Sports Med. 2017, 53, 478-486. [CrossRef]

6. Stratton, G.; Canoy, D.; Boddy, L.M.; Taylor, S.R.; Hackett, A.F.; Buchan, I.E. Cardiorespiratory Fitness and Body Mass Index of 9-11-Year-Old English Children: A Serial Cross-Sectional Study from 1998 to 2004. Int. J. Obes. 2007, 31, 1172-1178. [CrossRef] [PubMed]

7. Boddy, L.M.; Fairclough, S.J.; Hackett, A.F.; Stratton, G. Changes in Cardiorespiratory Fitness in 9- to 10.9-Year-Old Children: Sportslinx 1998-2010. Med. Sci. Sports Exerc. 2012, 44, 481-486. [CrossRef]

8. Knaeps, S.; Bourgois, J.G.; Charlier, R.; Mertens, E.; Lefevre, J.; Wijndaele, K. Ten-Year Change in Sedentary Behaviour, ModerateTo-Vigorous Physical Activity, Cardiorespiratory Fitness and Cardiometabolic Risk: Independent Associations and Mediation Analysis. Br. J. Sports Med. 2018, 52, 1063-1069. [CrossRef]

9. Brage, S.; Wedderkopp, N.; Ekelund, U.; Franks, P.W.; Wareham, N.J.; Andersen, L.B.; Froberg, K. Features of the Metabolic Syndrome Are Associated with Objectively Measured Physical Activity and Fitness in Danish Children: The European Youth Heart Study (EYHS). Diabetes Care 2004, 27, 2141-2148. [CrossRef] [PubMed]

10. Mäkelä, S.; Aaltonen, S.; Korhonen, T.; Rose, R.J.; Kaprio, J. Diversity of Leisure-Time Sport Activities in Adolescence as a Predictor of Leisure-Time Physical Activity in Adulthood. Scand. J. Med. Sci. Sport 2017, 27, 1902-1912. [CrossRef]

11. Telama, R.; Yang, X.; Viikari, J.; Välimäki, I.; Wanne, O.; Raitakari, O. Physical Activity from Childhood to Adulthood: A 21-Year Tracking Study. Am. J. Prev. Med. 2005, 28, 267-273. [CrossRef]

12. Department of Health and Social Care; Davies, D.S.C.; Atherton, F.; McBride, M.; Calderwood, C. UK Chief Medical Officers' Physical Activity Guidelines. 2019. Available online: https://assets.publishing.service.gov.uk/government/uploads/system/ uploads/attachment_data/file/832868/uk-chief-medical-officers-physical-activity-guidelines.pdf (accessed on 28 October 2021).

13. Sport England. Active Lives Children and Young People Survey Academic Year 2018/19. 2019. Available online: https://sportengland-production-files.s3.eu-west-2.amazonaws.com/s3fs-public/active-lives-children-survey-academicyear-18-19.pdf (accessed on 28 October 2021).

14. Janssen, I.; Boyce, W.F.; Simpson, K.; Pickett, W. Influence of Individual- and Area-Level Measures of Socioeconomic Status on Obesity, Unhealthy Eating, and Physical Inactivity in Canadian Adolescents. Am. J. Clin. Nutr. 2006, 83, 139-145. [CrossRef]

15. Lampinen, E.K.; Eloranta, A.M.; Haapala, E.A.; Lindi, V.; Väistö, J.; Lintu, N.; Karjalainen, P.; Kukkonen-Harjula, K.; Laaksonen, D.; Lakka, T.A. Physical Activity, Sedentary Behaviour, and Socioeconomic Status among Finnish Girls and Boys Aged 6-8 Years. Eur. J. Sport Sci. 2017, 14, 462-472. [CrossRef]

16. Wolfe, A.M.; Lee, J.A.; Laurson, K.R. Socioeconomic Status and Physical Fitness in Youth: Findings from the NHANES National Youth Fitness Survey. J. Sports Sci. 2020, 38, 534-541. [CrossRef]

17. Clennin, M.N.; Pate, R.R. The Association between Neighborhood Socioeconomic Deprivation, Cardiorespiratory Fitness, and Physical Activity in US Youth. J. Phys. Act. Health 2019, 16, 1147-1153. [CrossRef]

18. Talhout, R.; Schulz, T.; Florek, E.; van Benthem, J.; Wester, P.; Opperhuizen, A. Hazardous Compounds in Tobacco Smoke. Int. J. Environ. Res. Public Health 2011, 8, 613-628. [CrossRef] [PubMed]

19. Acuff, L.; Fristoe, K.; Hamblen, J.; Smith, M.; Chen, J. Third-Hand Smoke: Old Smoke, New Concerns. J. Community Health 2016, 41, 680-687. [CrossRef] [PubMed]

20. Environmental Protection Agency (US). Respiratory Health Effects of Passive Smoking: Lung Cancer and Other Disorders; Environmental Protection Agency (US): Washingotn, DC, USA, 1993.

21. Carreras, G.; Lugo, A.; Gallus, S.; Cortini, B.; Fernández, E.; López, M.J.; Soriano, J.B.; López-Nicolás, A.; Semple, S.; Gorini, G.; et al. Burden of Disease Attributable to Second-Hand Smoke Exposure: A Systematic Review. Prev. Med. 2019, 129, 105833. [CrossRef] 
22. Öberg, M.; Jaakkola, M.S.; Woodward, A.; Peruga, A.; Prüss-Ustün, A. Worldwide Burden of Disease from Exposure to SecondHand Smoke: A Retrospective Analysis of Data from 192 Countries. Lancet 2011, 377, 139-146. [CrossRef]

23. Stanaway, J.D.; Afshin, A.; Gakidou, E.; Lim, S.S.; Abate, D.; Al, E. Global, Regional, and National Comparative Risk Assessment of 84 Behavioural, Environmental and Occupational, and Metabolic Risks or Clusters of Risks for 195 Countries and Territories, 1990-2017: A Systematic Analysis for the Global Burden of Disease Stu. Lancet 2018, 392, 1923-1994. [CrossRef]

24. Longman, J.; Passey, M. Children, Smoking Households and Exposure to Second-Hand Smoke in the Home in Rural Australia: Analysis of a National Cross-Sectional Survey. BMJ Open 2013, 3, e003128. [CrossRef]

25. Lajunen, K.; Kalliola, S.; Kotaniemi-Syrjänen, A.; Pekka Malmberg, L.; Pelkonen, A.S.; Mäkelä, M.J. Environmental Tobacco Smoke Affects Lung Function of Preschoolers with Asthma Even after a Decade. Am. J. Respir. Crit. Care Med. 2019, 199, 534-536. [CrossRef]

26. Naeem, Z. Second-Hand Smoke-Ignored Implications. Int. J. Health Sci. 2015, 9, 5-6. [CrossRef]

27. Wang, Z.; May, S.M.; Charoenlap, S.; Pyle, R.; Ott, N.L.; Mohammed, K.; Joshi, A.Y. Effects of Secondhand Smoke Exposure on Asthma Morbidity and Health Care Utilization in Children: A Systematic Review and Meta-Analysis. Ann. Allergy Asthma Immunol. 2015, 115, 396-401. [CrossRef]

28. The National Archives. The Smoke-Free (Exemptions and Vehicles) Regulations 2007; The National Archives: Richmond, UK, 2007.

29. Jarvis, M.J.; Mindell, J.; Gilmore, A.; Feyerabend, C.; West, R. Smoke-Free Homes in England: Prevalence, Trends and Validation by Cotinine in Children. Tob. Control 2009, 18, 491-495. [CrossRef]

30. Office for National Statistics. Adult Smoking Habits in the UK: 2019; Office for National Statistics: London, UK, 2020.

31. Jarvis, M.J.; Feyerabend, C. Recent Trends in Children's Exposure to Second-Hand Smoke in England: Cotinine Evidence from the Health Survey for England. Addiction 2015, 110, 1484-1492. [CrossRef] [PubMed]

32. Moore, G.F.; Currie, D.; Gilmore, G.; Holliday, J.C.; Moore, L. Socioeconomic Inequalities in Childhood Exposure to Secondhand Smoke before and after Smoke-Free Legislation in Three UK Countries. J. Public Health 2012, 34, 599-608. [CrossRef] [PubMed]

33. McGee, C.E.; Trigwell, J.; Fairclough, S.J.; Murphy, R.C.; Porcellato, L.; Ussher, M.; Foweather, L. Influence of Family and Friend Smoking on Intentions to Smoke and Smoking-Related Attitudes and Refusal Self-Efficacy among 9-10 Year Old Children from Deprived Neighbourhoods: A Cross-Sectional Study. BMC Public Health 2015, 15, 225. [CrossRef] [PubMed]

34. Flouris, A.D.; Metsios, G.S.; Carrill, A.E.; Jamurtas, A.Z.; Stivaktakis, P.D.; Tzatzarakis, M.N.; Tsatsakis, A.M.; Koutedakis, Y. Respiratory and Immune Response to Maximal Physical Exertion Following Exposure to Secondhand Smoke in Healthy Adults. PLoS ONE 2012, 7, e31880. [CrossRef]

35. Flouris, A.D.; Koutedakis, Y. Immediate and Short-Term Consequences of Secondhand Smoke Exposure on the Respiratory System. Curr. Opin. Pulm. Med. 2011, 17, 110-115. [CrossRef]

36. De Borba, A.T.; Jost, R.T.; Gass, R.; Nedel, F.B.; Cardoso, D.M.; Pohl, H.H.; Reckziegel, M.B.; Corbellini, V.A.; Paiva, D.N. The Influence of Active and Passive Smoking on the Cardiorespiratory Fitness of Adults. Multidiscip. Respir. Med. $2014,9,34$. [CrossRef]

37. Papathanasiou, G.; Mamali, A.; Papafloratos, S.; Zerva, E. Effects of Smoking on Cardiovascular Function: The Role of Nicotine and Carbon Monoxide. Health Sci. J. 2014, 8, 272-288.

38. Magnússon, K.T.; Sveinsson, T.; Arngrimsson, S.Á.; Johannsson, E. Predictors of Fatness and Physical Fitness in Nine-Year-Old Icelandic School Children. Int. J. Pediatr. Obes. 2008, 3, 217-225. [CrossRef] [PubMed]

39. Hacke, C.; Weisser, B. Effects of Parental Smoking on Exercise Systolic Blood Pressure in Adolescents. J. Am. Heart Assoc. 2015, 4, e001936. [CrossRef] [PubMed]

40. Kaymaz, N.; Yildirim, S.; Tekin, M.; Aylanc, H.; Battal, F.; Topaloglu, N.; Binnetoglu, F.; Akbal, A. The Effects of Passive Smoking on the Six-Minute Walk Test in Obese Pediatric Cases. J. Clin. Res. Pediatr. Endocrinol. 2014, 6, 245-249. [CrossRef]

41. Audrain-McGovern, J.; Rodriguez, D.; Cuevas, J.; Sass, J. Initial Insight into Why Physical Activity May Help Prevent Adolescent Smoking Uptake. Drug Alcohol Depend. 2013, 132, 471-478. [CrossRef] [PubMed]

42. Horn, K.; Dino, G.; Branstetter, S.A.; Zhang, J.; Noerachmanto, N.; Jarrett, T.; Taylor, M. Effects of Physical Activity on Teen Smoking Cessation. Pediatrics 2011, 128, e801-e811. [CrossRef] [PubMed]

43. Parnell, M.; Gee, I.; Foweather, L.; Whyte, G.; Knowles, Z. Children of Smoking and Non-Smoking Households' Perceptions of Physical Activity, Cardiorespiratory Fitness, and Exercise. Children 2021, 8, 552. [CrossRef] [PubMed]

44. Ministry of Housing Communities \& Local Government. English Indices of Deprivation. 2019. Available online: http:/ /imd-bypostcode.opendatacommunities.org/imd/2019 (accessed on 28 October 2021).

45. Global Adult Tobacco Survey Collaborative Group. Tobacco Questions for Surveys: A Subset of Key Questions from the Global Adult Tobacco Survey (GATS), 2nd ed.; Centres for Disease Control and Prevention: Atalanta, GA, USA, 2011.

46. Cropsey, K.L.; Trent, L.R.; Clark, C.B.; Stevens, E.N.; Lahti, A.C.; Hendricks, P.S. How Low Should You Go? Determining the Optimal Cutoff for Exhaled Carbon Monoxide to Confirm Smoking Abstinence When Using Cotinine as Reference. Nicotine Tob. Res. 2014, 16, 1348-1355. [CrossRef]

47. Tual, S.; Piau, J.P.; Jarvis, M.J.; Dautzenberg, B.; Annesi-Maesano, I. Impact of Tobacco Control Policies on Exhaled Carbon Monoxide in Non-Smokers. J. Epidemiol. Community Health 2010, 64, 554-556. [CrossRef]

48. Deveci, S.E.; Deveci, F.; Açik, Y.; Ozan, A.T. The Measurement of Exhaled Carbon Monoxide in Healthy Smokers and Non-Smokers. Respir. Med. 2004, 98, 551-556. [CrossRef] [PubMed] 
49. Gourgoulianis, K.; Gogou, E.; Hamos, V.; Molyvdas, P. Indoor Maternal Smoking Doubles Adolescents' Exhaled Carbon Monoxide. Acta Paediatr. 2007, 91, 712-713. [CrossRef]

50. Marfell-Jones, M.; Olds, T.; Stewart, A.; Carter, L. Kinanthropometry IX: Proceedings of the 9th International Conference of the International Society for the Advancement of Kinanthropometry; Routledge: London, UK, 2006.

51. Lohman, T.G.; Roche, A.F.; Martorell, R. Anthropometric Standardization Reference Manual; Human Kinetics: Chicago, IL, USA, 1988.

52. Cole, T.J.; Lobstein, T. Extended International (IOTF) Body Mass Index Cut-Offs for Thinness, Overweight and Obesity. Pediatr. Obes. 2012, 7, 284-294. [CrossRef]

53. Mirwald, R.L.; Baxter-Jones, A.D.G.; Bailey, D.A.; Beunen, G.P. An Assessment of Maturity from Anthropometric Measurements. Med. Sci. Sports Exerc. 2002, 34, 689-694. [CrossRef] [PubMed]

54. Kowalski, K.C.; Crocker, P.R.E.; Donen, R.M. The Physical Activity Questionnaire for Older Children (PAQ-C) and Adolescents (PAQ-A) Manual; College of Kinesiology, University of Saskatchewan: Saskatoon, SK, Canada, 2004; pp. 1-37.

55. Biddle, S.J.H.; Gorely, T.; Pearson, N.; Bull, F.C. An Assessment of Self-Reported Physical Activity Instruments in Young People for Population Surveillance: Project ALPHA. Int. J. Behav. Nutr. Phys. Act. 2011, 8, 1. [CrossRef]

56. Voss, C.; Dean, P.H.; Gardner, R.F.; Duncombe, S.L.; Harris, K.C. Validity and Reliability of the Physical Activity Questionnaire for Children (PAQ-C) and Adolescents (PAQ-A) in Individuals with Congenital Heart Disease. PLoS ONE 2017, 12, e0175806. [CrossRef]

57. Eckel, S.P.; Linn, W.S.; Salam, M.T.; Bastain, T.M.; Zhang, Y.; Rappaport, E.B.; Liu, M.; Berhane, K. Spirometry Effects on Conventional and Multiple Flow Exhaled Nitric Oxide in Children. J. Asthma 2015, 52, 198-204. [CrossRef]

58. Dweik, R.A.; Boggs, P.B.; Erzurum, S.C.; Irvin, C.G.; Leigh, M.W.; Lundberg, J.O.; Olin, A.C.; Plummer, A.L.; Taylor, D.R. An Official ATS Clinical Practice Guideline: Interpretation of Exhaled Nitric Oxide Levels (FENO) for Clinical Applications. Am. J. Respir. Crit. Care Med. 2011, 184, 602-615. [CrossRef]

59. Arnold, R.J.; Massanari, M.; Lee, T.A.; Brooks, E. A Review of the Utility and Cost Effectiveness of Monitoring Fractional Exhaled Nitric Oxide (FeNO) in Asthma Management. Manag. Care 2018, 27, 34-41.

60. Hatziagorou, E.; Tsanakas, J. Assessment of Airway Inflammation with Exhaled NO Measurement. Hippokratia. 2007, 11, 51-62.

61. Quanjer, P.H.; Stanojevic, S.; Cole, T.J.; Baur, X.; Hall, G.L.; Culver, B.H.; Enright, P.L.; Hankinson, J.L.; Ip, M.S.M.; Zheng, J.; et al. Multi-Ethnic Reference Values for Spirometry for the 3-95-Yr Age Range: The Global Lung Function 2012 Equations. Eur. Respir. J. 2012, 40, 1324-1343. [CrossRef]

62. Korotzer, B.; Ong, S.; Hansen, J.E. Ethnic Differences in Pulmonary Function in Healthy Nonsmoking Asian- Americans and European-Americans. Am. J. Respir. Crit. Care Med. 2000, 1614 Pt 1, 1101-1108. [CrossRef]

63. Vandevoorde, J.; Verbanck, S.; Schuermans, D.; Kartounian, J.; Vincken, W. FEV1/FEV6and FEV6as an Alternative for FEV1/FVC and FVC in the Spirometric Detection of Airway Obstruction and Restriction. Chest 2005, 127, 1560-1564. [CrossRef]

64. Armstrong, N.; McManus, A.M. Aerobic Fitness. In Oxford Textbook of Children's Sport and Exercise Medicine; Armstrong, N., van Mechelen, W., Eds.; Oxford University Press: Oxford, UK, 2017; pp. 161-180.

65. Armstrong, N.; Winsley, R. Is Peak VO, a Maximal Index of Children's Aerobic Fitness? Int. J. Sports Med. 1996, 17, 356-359. [CrossRef] [PubMed]

66. Boddy, L.M.; Murphy, M.H.; Cunningham, C.; Breslin, G.; Foweather, L.; Gobbi, R.; Graves, L.E.F.; Hopkins, N.D.; Auth, M.K.H.; Stratton, G. Physical Activity, Cardiorespiratory Fitness, and Clustered Cardiometabolic Risk in 10- to 12-Year-Old School Children: The REACH Y6 Study. Am. J. Hum. Biol. 2014, 26, 446-451. [CrossRef] [PubMed]

67. Hopkins, N.; Stratton, G.; Maia, J.; Tinken, T.M.; Graves, L.E.; Cable, T.N.; Green, D.J. Heritability of Arterial Function, Fitness, and Physical Activity in Youth: A Study of Monozygotic and Dizygotic Twins. J. Pediatr. 2010, 157, 943-948. [CrossRef]

68. Yelling, M.; Lamb, K.L.; Swaine, I.L. Validity of a Pictorial Perceived Exertion Scale for Effort Estimation and Effort Production During Stepping Exercise in Adolescent Children. Eur. Phys. Educ. Rev. 2002, 8, 157-175. [CrossRef]

69. Daley, A.J.; Copeland, R.J.; Wright, N.P.; Wales, J.K.H. Protocol for: Sheffield Obesity Trial (SHOT): A Randomised Controlled Trial of Exercise Therapy and Mental Health Outcomes in Obese Adolescents [ISRCNT83888112]. BMC Public Health $2005,5,113$. [CrossRef]

70. Welsman, J.; Armstrong, N. Interpreting Aerobic Fitness in Youth: The Fallacy of Ratio Scaling. Pediatric Exerc. Sci. 2019, 31, 184-190. [CrossRef]

71. Lang, J.J.; Tremblay, M.S.; Ortega, F.B.; Ruiz, J.R.; Tomkinson, G.R. Review of Criterion-Referenced Standards for Cardiorespiratory Fitness: What Percentage of 1142026 International Children and Youth Are Apparently Healthy? Br. J. Sports Med. 2019, 53, 953-958. [CrossRef]

72. Field, A.P. Discovering Statistics Using IBM SPSS Statistics, 5th ed.; SAGE Publishing: Thousand Oaks, CA, USA, 2018.

73. Dukellis, D.; Zuk, J.; Pan, Z.; Morrison, J.E.; Friesen, R.H. Exhaled Carbon Monoxide Screening for Environmental Tobacco Smoke Exposure in Preanesthetic Children. Paediatr. Anaesth. 2009, 19, 848-853. [CrossRef] [PubMed]

74. Zeiher, J.; Ombrellaro, K.J.; Perumal, N.; Keil, T.; Mensink, G.B.M.; Finger, J.D. Correlates and Determinants of Cardiorespiratory Fitness in Adults: A Systematic Review. Sports Med. Open 2019, 5, 39. [CrossRef] [PubMed]

75. Gao, Y.; Chan, E.Y.Y.; Zhu, Y.; Wong, T.W. Adverse Effect of Outdoor Air Pollution on Cardiorespiratory Fitness in Chinese Children. Atmos. Environ. 2013, 64, 10-17. [CrossRef]

76. Biddle, S.J.H.; Atkin, A.J.; Cavill, N.; Foster, C. Correlates of Physical Activity in Youth: A Review of Quantitative Systematic Reviews. Int. Rev. Sport Exerc. Psychol. 2011, 4, 25-49. [CrossRef] 
77. O’Donoghue, G.; Kennedy, A.; Puggina, A.; Aleksovska, K.; Buck, C.; Burns, C.; Cardon, G.; Carlin, A.; Ciarapica, D.; Colotto, M.; et al. Socio-Economic Determinants of Physical Activity across the Life Course: A "DEterminants of DIet and Physical ACtivity" (DEDIPAC) Umbrella Literature Review. PLoS ONE 2018, 13, e0190737. [CrossRef] [PubMed]

78. Polak, M.; Szafraniec, K.; Kozela, M.; Wolfshaut-Wolak, R.; Bobak, M.; Pajak, A. Socioeconomic Status and Pulmonary Function, Transition from Childhood to Adulthood: Cross-Sectional Results from the Polish Part of the HAPIEE Study. BMJ Open 2019, 9, e022638. [CrossRef]

79. Laaksonen, M.; Rahkonen, O.; Karvonen, S.; Lahelma, E. Socioeconomic Status and Smoking: Analysing Inequalities with Multiple Indicators. Eur. J. Public Health 2005, 15, 262-269. [CrossRef]

80. Hiscock, R.; Bauld, L.; Amos, A.; Fidler, J.A.; Munafò, M. Socioeconomic Status and Smoking: A Review. Ann. N. Y. Acad. Sci. 2012, 1248, 107-123. [CrossRef] [PubMed]

81. Kaur, S.; Nieuwenhuijsen, M.J.; Colvile, R.N. Fine Particulate Matter and Carbon Monoxide Exposure Concentrations in Urban Street Transport Microenvironments. Atmos. Environ. 2007, 41, 4781-4810. [CrossRef]

82. Raub, J.A.; Mathieu-Nolf, M.; Hampson, N.B.; Thom, S.R. Carbon Monoxide Poisoning-A Public Health Perspective. Toxicology 2000, 145, 1-14. [CrossRef]

83. Florescu, A.; Ferrence, R.; Einarson, T.; Selby, P.; Soldin, O.; Koren, G. Methods for Quantification of Exposure to Cigarette Smoking and Environmental Tobacco Smoke: Focus on Developmental Toxicology. Ther. Drug Monit. 2009, 31, 14-30. [CrossRef] [PubMed]

84. Benowitz, N.L.; Bernert, J.T.; Caraballo, R.S.; Holiday, D.B.; Wang, J. Optimal Serum Cotinine Levels for Distinguishing Cigarette Smokers and Nonsmokers within Different Racial/Ethnic Groups in the United States between 1999 and 2004. Am. J. Epidemiol. 2009, 169, 236-248. [CrossRef]

85. Hukkanen, J.; Jacob, P.; Benowitz, N.L. Metabolism and Disposition Kinetics of Nicotine. Pharmacol. Rev. 2005, 57, 79-115. [CrossRef] [PubMed]

86. Semple, S.; Mueller, W.; Leyland, A.H.; Gray, L.; Cherrie, J.W. Assessing Progress in Protecting Non-Smokers from Secondhand Smoke. Tob. Control 2019, 28, 692-695. [CrossRef]

87. Kim, S. Overview of Cotinine Cutoff Values for Smoking Status Classification. Int. J. Environ. Res. Public Health 2016, 13, 1236. [CrossRef] [PubMed]

88. Tomkinson, G.R.; Lang, J.J.; Tremblay, M.S.; Dale, M.; Leblanc, A.G.; Belanger, K.; Ortega, F.B.; Léger, L. International Normative 20 m Shuttle Run Values from 1142026 Children and Youth Representing 50 Countries. Br. J. Sports Med. 2017, 51, 1545-1554. [CrossRef]

89. Benítez-Porres, J. Cut-off Values for Classifying Active Children and Adolescentes Using the Physical Activity Questionnaire: PAQ-C and PAQ-A. Nutr. Hosp. 2016, 33, 564. [CrossRef]

90. Noonan, R.J.; Boddy, L.M.; Knowles, Z.R.; Fairclough, S.J. Cross-Sectional Associations between High-Deprivation Home and Neighbourhood Environments, and Health-Related Variables among Liverpool Children. BMJ Open 2016, 6, e008693. [CrossRef]

91. Yu, C.C.W.; McManus, A.M.; Au, C.T.; So, H.K.; Chan, A.; Sung, R.Y.T.; Li, A.M. Appropriate Scaling Approach for Evaluating Peak VO 2 Development in Southern Chinese 8 to 16 Years Old. PLoS ONE 2019, 14, e0213674. [CrossRef]

92. Lolli, L.; Batterham, A.M.; Weston, K.L.; Atkinson, G. Size Exponents for Scaling Maximal Oxygen Uptake in Over 6500 Humans: A Systematic Review and Meta-Analysis. Sports Med. 2017, 47, 1405-1419. [CrossRef]

93. Armstrong, N.; Williams, J.; Balding, J.; Gentle, P.; Kirby, B. The Peak Oxygen Uptake of British Children with Reference to Age, Sex and Sexual Maturity. Eur. J. Appl. Physiol. Occup. Physiol. 1991, 62, 369-375. [CrossRef] [PubMed]

94. Sutton, N. The Assessment of Children's Anaerobic Performance; University of Exeter: Exeter, UK, 1999.

95. Cutrufello, P.T.; Smoliga, J.M.; Rundell, K.W. Small Things Make a Big Difference. Sports Med. 2012, 42, 1041-1058. [CrossRef] [PubMed]

96. Flouris, A.D.; Metsios, G.S.; Jamurtas, A.Z.; Koutedakis, Y. Cardiorespiratory and Immune Response to Physical Activity Following Exposure to a Typical Smoking Environment. Heart 2010, 96, 860-864. [CrossRef] [PubMed]

97. Doll, R.; Hill, A.B. Smoking and Carcinoma of the Lung. Br. Med. J. 1950, 2, 739-748. [CrossRef]

98. Doll, R.; Hill, A.B. The Mortality of Doctors in Relation to Their Smoking Habits: A Preliminary Report. BMJ 1954, 328, 1529-1533. [CrossRef]

99. Kaur, G.; Begum, R.; Thota, S.; Batra, S. A Systematic Review of Smoking-Related Epigenetic Alterations. Arch. Toxicol. 2019, 93, 2715-2740. [CrossRef]

100. Richmond, R.C.; Suderman, M.; Langdon, R.; Relton, C.L.; Smith, G.D. DNA Methylation as a Marker for Prenatal Smoke Exposure in Adults. Int. J. Epidemiol. 2018, 47, 1120-1130. [CrossRef]

101. Högberg, L.; Cnattingius, S.; Lundholm, C.; D’Onofrio, B.M.; Långström, N.; Iliadou, A.N. Effects of Maternal Smoking during Pregnancy on Offspring Blood Pressure in Late Adolescence. J. Hypertens. 2012, 30, 693-699. [CrossRef]

102. Koshy, G.; Delpisheh, A.; Brabin, B.J. Dose Response Association of Pregnancy Cigarette Smoke Exposure, Childhood Stature, Overweight and Obesity. Eur. J. Public Health 2011, 21, 286-291. [CrossRef]

103. DiFranza, J.R.; Aligne, C.A.; Weitzman, M. Prenatal and Postnatal Environmental Tobacco Smoke Exposure and Children's Health. Pediatrics 2004, 113, 1007-1015.

104. Berlin, I.; Oncken, C. Maternal Smoking during Pregnancy and Negative Health Outcomes in the Offspring. Nicotine Tob. Res. 2018, 20, 663-664. [CrossRef] 
105. Welk, G.J. The Youth Physical Activity Promotion Model: A Conceptual Bridge between Theory and Practice. Quest 1999, 51, 5-23. [CrossRef]

106. Wu, X.Y.; Han, L.H.; Zhang, J.H.; Luo, S.; Hu, J.W.; Sun, K. The Influence of Physical Activity, Sedentary Behavior on HealthRelated Quality of Life among the General Population of Children and Adolescents: A Systematic Review. PLoS ONE 2017, 12, e0187668. [CrossRef]

107. Ekelund, U.; Steene-Johannessen, J.; Brown, W.J.; Fagerland, M.W.; Owen, N.; Powell, K.E.; Bauman, A.; Lee, I.M.; Ding, D.; Heath, G.; et al. Does Physical Activity Attenuate, or Even Eliminate, the Detrimental Association of Sitting Time with Mortality? A Harmonised Meta-Analysis of Data from More than 1 Million Men and Women. Lancet 2016, 388, 1302-1310. [CrossRef]

108. Janz, K. Professor Kathleen Janz adds an "Active Voice" to Causes of Physical Inactivity. Available online: https: / / medicine.uiowa. edu/obesity/content/professor-kathleen-janz-adds-active-voice-causes-physical-inactivity (accessed on 25 February 2018).

109. Jat, K.R. Spirometry in Children. Prim. Care Respir. J. 2013, 22, 221-229. [CrossRef] [PubMed]

110. Hegewald, M.J.; Crapo, R.O. Socioeconomic Status and Lung Function. Chest 2007, 132, 1608-1614. [CrossRef]

111. Franklin, P.J. Indoor Air Quality and Respiratory Health of Children. Paediatr. Respir. Rev. 2007, 8, 281-286. [CrossRef]

112. Dales, R.; Wheeler, A.; Mahmud, M.; Frescura, A.M.; Smith-Doiron, M.; Nethery, E.; Liu, L. The Influence of Living near Roadways on Spirometry and Exhaled Nitric Oxide in Elementary Schoolchildren. Environ. Health Perspect. 2008, 116, 1423-1427. [CrossRef]

113. Braun, L. Race, Ethnicity and Lung Function: A Brief History. Can. J. Respir. Ther. 2015, 51, 99-101.

114. Schivinski, C.I.S.; de Assumpção, M.S.; de Figueiredo, F.C.X.S.; Wamosy, R.M.G.; Ferreira, L.G.; Ribeiro, J.D. Impulse Oscillometry, Spirometry, and Passive Smoking in Healthy Children and Adolescents. Rev. Port. Pneumol. Engl. Ed. 2017, 23, 311-316. [CrossRef] [PubMed]

115. Bird, Y.; Staines-Orozco, H. Pulmonary Effects of Active Smoking and Secondhand Smoke Exposure among Adolescent Students in Juárez, Mexico. Int. J. COPD 2016, 11, 1459-1467. [CrossRef]

116. Moshammer, H.; Hoek, G.; Luttmann-Gibson, H.; Neuberger, M.A.; Antova, T.; Gehring, U.; Hruba, F.; Pattenden, S.; Rudnai, P.; Slachtova, H.; et al. Parental Smoking and Lung Function in Children: An International Study. Am. J. Respir. Crit. Care Med. 2006, 173, 1255-1263. [CrossRef]

117. Li, Y.F.; Gilliland, F.D.; Berhane, K.; McConnell, R.; Gauderman, W.J.; Rappaport, E.B.; Peters, J.M. Effects of in Utero and Environmental Tobacco Smoke Exposure on Lung Function in Boys and Girls with and without Asthma. Am. J. Respir. Crit. Care Med. 2000, 162, 2097-2104. [CrossRef]

118. Thacher, J.D.; Schultz, E.S.; Hallberg, J.; Hellberg, U.; Kull, I.; Thunqvist, P.; Pershagen, G.; Gustafsson, P.M.; Melén, E.; Bergström, A. Tobacco Smoke Exposure in Early Life and Adolescence in Relation to Lung Function. Eur. Respir. J. 2018, 51, 1702111. [CrossRef] [PubMed]

119. Gilliland, F.D.; Berhane, K.; McConnell, R.; Gauderman, W.J.; Vora, H.; Rappaport, E.B.; Avol, E.; Peters, J.M. Maternal Smoking during Pregnancy, Environmental Tobacco Smoke Exposure and Childhood Lung Function. Thorax 2000, 55, 271-276. [CrossRef] [PubMed]

120. Kuo, C.R.W.; Spears, M.; Haughney, J.; Smith, A.; Miller, J.; Bradshaw, T.; Murray, L.; Williamson, P.; Lipworth, B. Scottish Consensus Statement on the Role of FeNO in Adult Asthma. Respir. Med. 2019, 155, 54-57. [CrossRef] [PubMed]

121. Brody, D.J.; Zhang, X.; Kit, B.K.; Dillon, C.F. Reference Values and Factors Associated with Exhaled Nitric Oxide: U.S. Youth and Adults. Respir. Med. 2013, 107, 1682-1691. [CrossRef]

122. Bjermer, L.; Alving, K.; Diamant, Z.; Magnussen, H.; Pavord, I.; Piacentini, G.; Price, D.; Roche, N.; Sastre, J.; Thomas, M.; et al. Current Evidence and Future Research Needs for FeNO Measurement in Respiratory Diseases. Respir. Med. 2014, 108, 830-841. [CrossRef]

123. Karimi, L.; Vijverberg, S.J.H.; Farzan, N.; Ghanbari, M.; Verhamme, K.M.C.; Maitland-van der Zee, A.H. FCER2 T2206C Variant Associated with FENO Levels in Asthmatic Children Using Inhaled Corticosteroids: The PACMAN Study. Clin. Exp. Allergy 2019, 49, 1429-1436. [CrossRef]

124. Kingwell, B.A. Nitric Oxide-mediated Metabolic Regulation during Exercise: Effects of Training in Health and Cardiovascular Disease. FASEB J. 2000, 14, 1685-1696. [CrossRef] [PubMed]

125. Shannon, O.M.; Duckworth, L.; Barlow, M.J.; Woods, D.; Lara, J.; Siervo, M.; O'Hara, J.P. Dietary Nitrate Supplementation Enhances High-Intensity Running Performance in Moderate Normobaric Hypoxia, Independent of Aerobic Fitness. Nitric Oxide Biol. Chem. 2016, 59, 63-70. [CrossRef] [PubMed]

126. Bailey, S.J.; Winyard, P.; Vanhatalo, A.; Blackwell, J.R.; DiMenna, F.J.; Wilkerson, D.P.; Tarr, J.; Benjamin, N.; Jones, A.M. Dietary Nitrate Supplementation Reduces the O2 Cost of Low-Intensity Exercise and Enhances Tolerance to High-Intensity Exercise in Humans. J. Appl. Physiol. 2009, 107, 1144-1155. [CrossRef] [PubMed]

127. Ahovuo-Saloranta, A.; Csonka, P.; Lehtimäki, L. Basic Characteristics and Clinical Value of FeNO in Smoking Asthmatics-A Systematic Review. J. Breath Res. 2019, 13, 034003. [CrossRef] [PubMed]

128. Zhou, Y.; Liu, Y.; Sun, H.; Ma, J.; Xiao, L.; Cao, L.; Li, W.; Wang, B.; Yuan, J.; Chen, W. Associations of Urinary Polycyclic Aromatic Hydrocarbon Metabolites with Fractional Exhaled Nitric Oxide and Exhaled Carbon Monoxide: A Cross-Sectional Study. Sci. Total Environ. 2018, 618, 542-550. [CrossRef] [PubMed]

129. Jacinto, T.; Malinovschi, A.; Janson, C.; Fonseca, J.; Alving, K. Differential Effect of Cigarette Smoke Exposure on Exhaled Nitric Oxide and Blood Eosinophils in Healthy and Asthmatic Individuals. J. Breath Res. 2017, 11, 036006. [CrossRef] [PubMed] 
130. Matsunaga, K.; Kuwahira, I.; Hanaoka, M.; Saito, J.; Tsuburai, T.; Fukunaga, K.; Matsumoto, H.; Sugiura, H.; Ichinose, M. An Official JRS Statement: The Principles of Fractional Exhaled Nitric Oxide (FeNO) Measurement and Interpretation of the Results in Clinical Practice. Respir. Investig. 2021, 59, 34-52. [CrossRef] 